\title{
Hydrogen Sulfide Alleviates Lipopolysaccharide-Induced Diaphragm Dysfunction in Rats by Reducing Apoptosis and Inflammation through ROS/MAPK and TLR4/NF- $\kappa$ B Signaling Pathways
}

\author{
Guo-Yu Zhang, ${ }^{1}$ Dan Lu, ${ }^{2,3}$ Shao-Feng Duan, ${ }^{3,4}$ Ying-Ran Gao, ${ }^{2,3}$ Shi-Yu Liu, ${ }^{2,3}$ Ya Hong, \\ Peng-Zhen Dong, ${ }^{2,3}$ Ya-Ge Chen, ${ }^{2,3}$ Tao Li, ${ }^{2,3}$ Da-Yong Wang, ${ }^{1}$ Xiang-Shu Cheng, ${ }^{5}$ Fei He, ${ }^{5}$ \\ Jian-She Wei, ${ }^{3,6}$ Guang-Yu Li, ${ }^{7}$ Qing-Yong Zhang, ${ }^{8}$ Dong-Dong Wu $\mathbb{D}^{2},{ }^{2,3}$ \\ and Xin-Ying Ji $\mathbb{D}^{2,3,9}$ \\ ${ }^{1}$ The First Affiliated Hospital of Henan University, Kaifeng, Henan 475001, China \\ ${ }^{2}$ School of Basic Medical Sciences, Henan University College of Medicine, Kaifeng, Henan 475004, China \\ ${ }^{3}$ Henan International Joint Laboratory for Nuclear Protein Regulation, Henan University, Kaifeng, Henan 475004, China \\ ${ }^{4}$ College of Pharmacy, Henan University, Kaifeng, Henan 475004, China \\ ${ }^{5}$ Huaihe Hospital of Henan University, Kaifeng, Henan 475000, China \\ ${ }^{6}$ Brain Research Laboratory, College of Life Sciences, Henan University, Kaifeng, Henan 475004, China \\ ${ }^{7}$ Department of Microbiology and Immunology, School of Medicine, University of Texas Medical Branch, Galveston, TX 77555, USA \\ ${ }^{8}$ The Second Affiliated Hospital of Zhengzhou University, Zhengzhou, Henan 450014, China \\ ${ }^{9}$ Henan Provincial People's Hospital Affiliated to Henan University, Zhengzhou, Henan 450003, China
}

Correspondence should be addressed to Dong-Dong Wu; dongyangwu2007@sina.com and Xin-Ying Ji; xinying_ji@henu.edu.cn

Received 25 January 2018; Revised 11 April 2018; Accepted 29 April 2018; Published 24 May 2018

Academic Editor: Eric E. Kelley

Copyright (c) 2018 Guo-Yu Zhang et al. This is an open access article distributed under the Creative Commons Attribution License, which permits unrestricted use, distribution, and reproduction in any medium, provided the original work is properly cited.

Diaphragm dysfunction is an important clinical problem worldwide. Hydrogen sulfide $\left(\mathrm{H}_{2} \mathrm{~S}\right)$ is involved in many physiological and pathological processes in mammals. However, the effect and mechanism of $\mathrm{H}_{2} \mathrm{~S}$ in diaphragm dysfunction have not been fully elucidated. In this study, we detected that the level of $\mathrm{H}_{2} \mathrm{~S}$ was decreased in lipopolysaccharide- (LPS-) treated L6 cells. Treatment with $\mathrm{H}_{2} \mathrm{~S}$ increased the proliferation and viability of LPS-treated L6 cells. We found that $\mathrm{H}_{2} \mathrm{~S}$ decreased reactive oxygen species(ROS-) induced apoptosis through the mitogen-activated protein kinase (MAPK) signaling pathway in LPS-treated L6 cells. Administration of $\mathrm{H}_{2} \mathrm{~S}$ alleviated LPS-induced inflammation by mediating the toll-like receptor-4 (TLR-4)/nuclear factor-kappa B (NF- $\kappa \mathrm{B}$ ) signaling pathway in L6 cells. Furthermore, $\mathrm{H}_{2} \mathrm{~S}$ improved diaphragmatic function and structure through the reduction of inflammation and apoptosis in the diaphragm of septic rats. In conclusion, these findings indicate that $\mathrm{H}_{2} \mathrm{~S}$ ameliorates LPSinduced diaphragm dysfunction in rats by reducing apoptosis and inflammation through ROS/MAPK and TLR4/NF- $\kappa \mathrm{B}$ signaling pathways. Novel slow-releasing $\mathrm{H}_{2} \mathrm{~S}$ donors can be designed and applied for the treatment of diaphragm dysfunction.

\section{Introduction}

The diaphragm is a dome-shaped skeletal muscle in mammals that is mainly required for respiratory function $[1,2]$. Pleural pressure is decreased by the contraction of the diaphragm, which makes the inspiration step of ventilation possible. Therefore, the efficiency of respiration is partly determined by the contractile performance of the diaphragm [3]. Diaphragm dysfunction is involved in a number of clinical conditions, including interstitial lung disease, chronic obstructive pulmonary disease, heart failure, spinal cord injury, critical illness and mechanical ventilation, and neuromuscular disease [4-9]. An increasing number of studies indicate that diaphragm dysfunction has been linked to 
impaired exercise tolerance, increased breathlessness, prolonged and difficult weaning from mechanical ventilation, and adverse health outcomes [10-12].

Hydrogen sulfide $\left(\mathrm{H}_{2} \mathrm{~S}\right)$ has been considered the third gaseous signaling molecule, accompanying nitric oxide, and carbon monoxide $[13,14] . \mathrm{H}_{2} \mathrm{~S}$ can be endogenously produced from L-cysteine (L-Cys) and homocysteine in mammals mainly by two pyridoxal- $5^{\prime}$-phosphate- (PLP-) dependent enzymes, namely cystathionine $\gamma$-lyase (CSE) and cystathionine $\beta$-synthase (CBS) [15-17]. 3-Mercaptopyruvate sulfurtransferase (3-MST), a PLP-independent enzyme, acts in combination with cysteine aminotransferase to produce $\mathrm{H}_{2} \mathrm{~S}$ from L-Cys in the presence of $\alpha$-ketoglutarate $[15,18]$. There is increasing evidence that $\mathrm{H}_{2} \mathrm{~S}$ plays important roles in a wide range of physiological and pathological conditions $[13,16,18]$. In the respiratory system, $\mathrm{H}_{2} \mathrm{~S}$ has been shown to regulate many important functions such as pulmonary circulation, airway tone, fibrosis, cell proliferation or apoptosis, oxidative stress, and inflammation [19-21]. However, the effect and mechanism of $\mathrm{H}_{2} \mathrm{~S}$ in diaphragm dysfunction have not been fully elucidated.

Sepsis is a life-threatening organ dysfunction caused by a dysregulated host response to infection [22, 23]. A number of studies have indicated that sepsis could induce diaphragm dysfunction, which can be attributed to the localized elaboration of cytokines within the diaphragm [24-26]. Lipopolysaccharide (LPS) is one of the cell wall components of most Gram-negative bacteria and acts as a potent initiator of inflammation [27, 28]. Recently, LPS has been widely adopted to induce septic diaphragm dysfunction in many different animal models $[24,27,29]$. In the present study, we detected the protein expressions of $\mathrm{H}_{2} \mathrm{~S}$-generating enzymes and the level of endogenous $\mathrm{H}_{2} \mathrm{~S}$ in LPS-treated skeletal muscle cells, and further determined the effect of exogenous $\mathrm{H}_{2} \mathrm{~S}$ on diaphragm dysfunction and clarified the associated molecular mechanism.

\section{Materials and Methods}

2.1. Cell Culture. Rat skeletal muscle cell line L6 was obtained from the Institute of Biochemistry and Cell Biology, Chinese Academy of Sciences (IBCB, CAS, Shanghai, China) and maintained in Dulbecco's modified Eagle's medium (DMEM) supplemented with $10 \%$ fetal calf serum, $100 \mathrm{U} / \mathrm{ml}$ penicillin, and $100 \mu \mathrm{g} / \mathrm{ml}$ streptomycin. Cells were cultured in a humidified incubator with $5 \% \mathrm{CO}_{2}$ and $95 \%$ air at $37^{\circ} \mathrm{C}$. Confluent L6 cells were transferred to serum-free DMEM medium for overnight starvation before each experiment. The cells were divided into three groups: control group, LPS group, and $\mathrm{LPS}+\mathrm{H}_{2} \mathrm{~S}$ group. The control group was treated with phosphate-buffered saline (PBS) and the LPS group was treated with $250 \mu \mathrm{g} / \mathrm{ml}$ LPS (dissolved in PBS). The LPS $+\mathrm{H}_{2} \mathrm{~S}$ group was treated with $250 \mu \mathrm{g} / \mathrm{ml}$ LPS and $100 \mu \mathrm{M}$ $\mathrm{NaHS}$ (an $\mathrm{H}_{2} \mathrm{~S}$ donor, dissolved in PBS). After $24 \mathrm{~h}$ of treatment, the cells were then used for subsequent experiments.

2.2. Measurement of $\mathrm{H}_{2} \mathrm{~S}$ Levels. The concentrations of $\mathrm{H}_{2} \mathrm{~S}$ in L6 cells and culture supernatant were measured using an enzyme-linked immunosorbent assay (ELISA) kit (LanpaiBio, Shanghai, China) as previously described [30].

2.3. Cell Growth Assay. The 5-ethynyl-2'-deoxyuridine (EdU) incorporation assay was performed using the CellLight EdU Apollo 567 In Vitro Imaging Kit (RiboBio, Guangzhou, Guangdong, China) according to the manufacturer's instructions. Cell proliferation rate $=($ EdU-positive cells) $/$ (total number of cells $) \times 100 \%$. The cell viability was detected using the CellTiter $96 \mathrm{AQ}_{\text {ueous }}$ One Solution Cell Proliferation Assay kit (MTS; Promega, Madison, WI, USA) according to the manufacturer's protocols. The cell viability was expressed as a percentage of the untreated control.

2.4. Cellular Apoptosis Analysis. Cellular apoptosis was analyzed by the in situ terminal deoxynucleotidyl transferasemediated dUTP nick end labeling (TUNEL) assay using a cell death detection kit (Beyotime Institute of Biotechnology, Shanghai, China) following the manufacturer's instructions. Briefly, cells were fixed with $4 \%$ paraformaldehyde, permeabilized with $0.1 \%$ Triton X-100, incubated with $50 \mu \mathrm{l}$ TUNEL reaction mixture for $60 \mathrm{~min}$ at $37^{\circ} \mathrm{C}$ in darkness and then rinsed with PBS three times. After counterstaining with $5 \mathrm{mg} / \mathrm{ml}$ DAPI for $5 \mathrm{~min}$ at room temperature, cells were photographed with a fluorescent microscope (Eclipse Ti, Nikon, Melville, NY, USA) from six random fields. The apoptotic index $=($ positively stained apoptotic cells $) /($ total number of cells) $\times 100 \%$.

2.5. Detection of Intracellular Reactive Oxygen Species (ROS). Intracellular ROS generation was detected by using a $2^{\prime}, 7^{\prime}$-dichlorofluorescin diacetate- (DCF-DA-) Cellular Reactive Oxygen Species Detection Assay Kit (Beyotime Institute of Biotechnology, Shanghai, China). Cells were incubated with $10 \mu \mathrm{M}$ DCF-DA for $30 \mathrm{~min}$ in darkness at $37^{\circ} \mathrm{C}$ and washed three times with PBS. The fluorescence was observed under a fluorescent microscope (Eclipse $\mathrm{Ti}$, Nikon, Melville, NY, USA) from six random fields and measured by Image J software (National Institutes of Health, Bethesda, MD, USA).

2.6. Antioxidant Activity Determination. The activities of superoxide dismutase (SOD), glutathione peroxidase (GSH$\mathrm{Px}$ ), and catalase (CAT) in L6 cells were measured using commercial kits (Beyotime Institute of Biotechnology, Shanghai, China) according to the manufacturer's instructions.

2.7. Biochemical Analysis. The contents of IL-6, IL-10, and IL-18 in L6 cells were determined using commercial ELISA kits (Elabscience, Wuhan, Hubei, China) according to the manufacturer's protocols.

2.8. Western Blotting. Total protein was extracted from L6 cells. Western blotting was performed to detect the target proteins. The primary antibodies, including anti-CSE, antiCBS, anti-3-MST, anti-B-cell lymphoma-2 (Bcl-2), anti-Bcell lymphoma-extra large (Bcl-xl), anti-Bcl-2-associated $\mathrm{X}$ protein (Bax), anti-Bcl-xl/Bcl-2-associated death promoter 
(Bad), anti-cleaved caspase-3, anti-cleaved caspase-8, anticleaved caspase- 9 , anti-cleaved polyadenosine diphosphateribose polymerase (PARP), and anti-glyceraldehyde-3phosphate dehydrogenase (GAPDH) antibodies were purchased from Proteintech (Chicago, IL, USA). Antiextracellular signal-regulated protein kinase 1/2 (ERK1/2), anti-phospho (p)-ERK1/2 (Thr202/Tyr204), anti-p38, antip-p38 (Thr180/Tyr182), anti-c-Jun N-terminal kinase (JNK), anti-p-JNK (Thr183/Tyr185), anti-toll-like receptor4 (TLR-4), anti-transforming growth factor-activated kinase-1 (TAK1), anti-p-TAK1 (Ser412), anti-inhibitor of nuclear factor kappa-B kinase (IKK) subunit alpha (IKK $\alpha$ ), anti-IKK subunit $\beta$ (IKK $\beta)$, anti-p-IKK $\alpha / \beta$ (Ser176/180), anti-nuclear factor of kappa light polypeptide gene enhancer in B-cell inhibitor, alpha ( $\mathrm{I} \kappa \mathrm{B} \alpha)$, anti-p-I $\kappa \mathrm{B} \alpha$ (Ser32), anti-p50, anti-p65, anti-p-p65 (Ser536), and the horseradish peroxidase-conjugated secondary antibody were purchased from Cell Signaling Technology (CST, Danvers, MA, USA). Results were normalized to the level of GAPDH. The reaction was visualized using an enhanced chemiluminescence system (Thermo Fisher Scientific, Rockford, IL, USA). The bands were semiquantified with Image J software.

2.9. Animal Study. Animal experiments were approved by the Committee of Medical Ethics and Welfare for Experimental Animals of Henan University School of Medicine in compliance with the Experimental Animal Regulations formulated by the National Science and Technology Commission, China (HUSOM-2017-198). All animal experiments were conducted in accordance with the committee's approved guidelines. Eighteen male Wistar rats (6-8 weeks old), initially weighing 180-220 g, were purchased from Beijing Vital River Laboratory Animal Technology Co., Ltd. (Beijing, China). Rats were housed in individual cages in a temperature- and humidity-controlled room with a 12-hour light/dark cycle. All rats were fed standard pellet food and distilled water ad libitum and allowed to acclimatize to new surroundings for one week prior to the study. Animal studies were performed as previously described with minor modifications [24]. Briefly, rats received an intraperitoneal (i.p.) injection of $5 \mathrm{mg} / \mathrm{kg}$ LPS which was dissolved in normal saline (NS) to induce diaphragm dysfunction. A normal control group was also allocated. Subsequently, the rats from the control and LPS groups received an i.p. injection of NS and the rats from the LPS $+\mathrm{H}_{2} \mathrm{~S}$ group received an i.p. injection of $\mathrm{NaHS}$ $(100 \mu \mathrm{mol} / \mathrm{kg}$, dissolved in NS).

2.10. Diaphragm Contractile Measurements. Twenty-four hours after the administration of NaHS or NS, all rats were killed and the body weight change was measured. The right hemidiaphragm was quickly removed and immediately immersed in Krebs solution that was continuously aerated with $95 \% \mathrm{O}_{2} / 5 \% \mathrm{CO}_{2}$ and contained the following (mmol/l): $135 \mathrm{NaCl}, 5 \mathrm{KCl}, 2.5 \mathrm{CaCl}_{2}, 1 \mathrm{MgSO}_{4}$, $1 \mathrm{NaH}_{2} \mathrm{PO}_{4}, 15 \mathrm{NaHCO}_{3}$, and 1 glucose, with a pH of 7.4. A diaphragm muscle strip ( $5 \mathrm{~mm}$ wide) was obtained from the midcostal region of the right diaphragm by careful dissection parallel to the long axis of the fibers. The muscle strip was suspended vertically in a $37^{\circ} \mathrm{C}$ tissue bath containing Krebs solution. The end of the muscle was tied to a rigid support. The muscle tendon was connected to an isometric force transducer mounted on a micrometer.

Two silver stimulating electrodes were placed parallel to the muscle strip. After equilibration for $15 \mathrm{~min}$, isometric contractions were recorded at the optimal muscle length (L0) at which the peak twitch force was observed. Stimuli were applied using a rectangular $0.2 \mathrm{~ms}$ duration pulse and a train duration of $250 \mathrm{~ms}$. To ensure supramaximal stimulation, the strips were stimulated at $20 \%$ above voltage to obtain maximal forces. The signal was amplified and recorded using a data acquisition system (MedLab, Nanjing, Jiangsu, China). Once maximal stimulus intensity and the L0 for force production were determined, peak twitch tension was determined at L0 from a series of contractions induced by single-pulse stimuli and maximal rate of contraction $\left(+d T / d t_{\max }\right)$ and maximal rate of relaxation $\left(-d T / d t_{\max }\right)$ were measured. Maximal tetanic tension was produced by a supramaximal $250 \mathrm{~ms}$ stimulus train at $100 \mathrm{~Hz}$. To measure the force-frequency response, each strip was stimulated with a $250 \mathrm{~ms}$ train at 10,20,40, 60 , and $100 \mathrm{~Hz}$, with at least a 2 min interval between each stimulus train. The fatigue index of the diaphragm was assessed by a series of 150 tetanic contractions $(400 \mathrm{~ms}$ contraction times at $10,20,40,60$, and $100 \mathrm{~Hz}$ once every second). The fatigue index was calculated from the ratio of the force produced during the 150th contraction relative to the 1st contraction [31]. After the measurements were taken, the muscle strip was blotted dry and weighed. The forces were normalized to muscle cross-sectional area (CSA) and expressed as specific force $\left(\mathrm{N} / \mathrm{cm}^{2}\right)$. Tissue CSA was estimated using measurements of muscle length $(\mathrm{cm})$, mass $(\mathrm{g})$, and density $\left(1.056 \mathrm{~g} / \mathrm{cm}^{3}\right)$. The left costal hemidiaphragm was used for biochemical and molecular experiments, or embedded in FSC 22 frozen section compound (Leica, Buffalo Grove, IL, USA) for histological staining.

2.11. Quantitative Real-Time Polymerase Chain Reaction ( $q R T-P C R)$. Total RNA was isolated from diaphragmatic muscle tissues using a TRIzol reagent, treated with DNase I, and purified using an RNA clean-up kit (Cwbiotech, Beijing, China). Total RNA ( $1 \mu \mathrm{g})$ was applied for cDNA synthesis using a cDNA reverse transcription kit (Cwbiotech, Beijing, China). Primers were designed according to the primer design principles with Primer Premier 5.0 (Premier Biosoft, Palo Alto, CA, USA). The sequences of primers were listed in Table 1. The reactions were performed in a total volume of $20 \mu \mathrm{l}$ using the following thermal cycling parameters: $95^{\circ} \mathrm{C}$ for $10 \mathrm{~min}, 40$ cycles of $95^{\circ} \mathrm{C}$ for $15 \mathrm{~s}, 60^{\circ} \mathrm{C}$ for $60 \mathrm{~s}$, and $72^{\circ} \mathrm{C}$ for $1 \mathrm{~min}$. The results were normalized to the level of GAPDH.

2.12. Histological Analysis. A necropsy examination was performed immediately after the rats were sacrificed. Diaphragmatic muscle tissues were fixed in $10 \%$ neutral buffered formalin, embedded in paraffin, sectioned at $5 \mu \mathrm{m}$ thickness, 
Table 1: Primers used in this study.

\begin{tabular}{lcc}
\hline Genes & Sense primers $\left(5^{\prime}-3^{\prime}\right)$ & Antisense primers $\left(5^{\prime}-3^{\prime}\right)$ \\
\hline TNF- $\alpha$ & GAAAGCATGATCCGAGATGTGGAA & CAGTAGACAGAAGAGCGTGGTGGC \\
MCP-1 & CTATGCAGGTCTCTGTCACGCTTC & CAGCCGACTCATTGGGATCA \\
IL-1 $\beta$ & TGCAGGCTTCGAGATGAA & AGGCCACAGGGATTTTGTC \\
IL-6 & ACAGCCACTGCCTTCCCTAC & GAATTGCCATTGCACAACTCTT \\
IL-10 & CCTCTGGATACAGCTGCGAC & CAGTAGATGCCGGGTGGTTC \\
IL-18 & GACCGAACAGCCAACGAATC & GATAGGGTCACAGCCAGTCC \\
GAPDH & CGTGTTCCTACCCCCAATGTA & CACAGGAGACAACCTGGTCC \\
\hline
\end{tabular}

and processed according to the hematoxylin and eosin (HE) staining protocols. Diaphragmatic muscle tissues were then stained with anti-myosin heavy chain (MHC) Type I, anti-MHC Type IIa, anti-Ki67, and anti-cleaved caspase 3 antibodies (CST, Danvers, MA, USA), followed by incubation with a secondary antibody. Diaphragmatic muscle tissues were observed using a Zeiss Axioskop 2 plus microscope (Carl Zeiss, Thornwood, NY, USA). The cross-sectional area (CSA) of a diaphragm muscle fiber was determined according to a previous study [32]. The proliferation index (PI) was determined by the number of Ki67 positive cells among the total number of cells [33]. Furthermore, apoptosis rate was estimated as cleaved caspase 3 positive cells/total cells [34].

2.13. Statistical Analysis. All results were presented as the mean \pm standard error of the mean (SEM). Statistical differences were analyzed by one-way analysis of variance (ANOVA) using SPSS 17.0 software, followed by an LSD post hoc test. A $P$ value of less than 0.05 was considered to be statistically significant.

\section{Results}

3.1. The Level of $\mathrm{H}_{2} \mathrm{~S}$ Is Decreased in LPS-Treated L6 Cells and Administration of $\mathrm{H}_{2} \mathrm{~S}$ Increases the Growth of LPS-Treated L6 Cells. As shown in Figures 1(a)-1(d), the protein levels of CSE, CBS, and 3-MST in LPS-treated L6 cells were lower than those in untreated L6 cells. In addition, the levels of $\mathrm{H}_{2} \mathrm{~S}$ in LPS-treated L6 cells, as well as in the supernatant, were lower than those in untreated L6 cells and the supernatant (Figures 1(e) and 1(f)). These results suggest that $\mathrm{H}_{2} \mathrm{~S}$ may play an important role in the growth of L6 cells. To test this hypothesis, we determined the effect of exogenous $\mathrm{H}_{2} \mathrm{~S}$ on the growth of LPS-treated L6 cells. The proliferation and viability of L6 cells were inhibited by the treatment of LPS, while $100 \mu \mathrm{M}$ NaHS enhanced the proliferation and viability of LPS-treated L6 cells (Figures 1(g)-1(i)).

3.2. $\mathrm{H}_{2} \mathrm{~S}$ Reduces Apoptosis in LPS-Treated L6 Cells. As shown in Figures 2(a) and 2(b), the apoptotic index increased in the LPS group compared with the control group. Administration of $\mathrm{H}_{2} \mathrm{~S}$ decreased the apoptotic index in the LPS group. The ratios of $\mathrm{Bax} / \mathrm{Bcl}-2$ and $\mathrm{Bad} / \mathrm{Bcl}-\mathrm{xl}$ have been widely considered important factors in the regulation of apoptosis. In mammalian cells, increased $\mathrm{Bad} / \mathrm{Bcl}-\mathrm{xl}$ and $\mathrm{Bax} / \mathrm{Bcl}-2$ ratios are common phenomena in mitochondrial apoptosis $[35,36]$. As shown in Figures 2(c), 2(e), and 2(f), the Bax/ $\mathrm{Bcl}-2$ and $\mathrm{Bad} / \mathrm{Bcl}-\mathrm{xl}$ ratios increased in the LPS group compared with the control group and decreased in the LPS $+\mathrm{H}_{2} \mathrm{~S}$ group compared with the LPS group. Furthermore, the protein expression levels of cleaved caspase-3, -8 , and -9 and cleaved PARP showed similar trends (Figures 2(d), $2(\mathrm{~g})-2(\mathrm{j}))$. In sum, these results indicate that the apoptotic level in LPS-treated L6 cells is increased and administration of $\mathrm{H}_{2} \mathrm{~S}$ significantly reduces the apoptotic level.

3.3. $\mathrm{H}_{2} \mathrm{~S}$ Mediates the ROS/Mitogen-Activated Protein Kinase (MAPK) Signaling Pathway in L6 Cells. ROS are formed upon partial reduction of oxygen, including hydrogen peroxide, superoxide anion, singlet oxygen, and hydroxyl radical [37]. Enzymatic ROS-scavenging mechanisms include a number of antioxidant enzymes such as SOD, GSH-Px, and CAT $[37,38]$. Compared to the control group, the levels of ROS were increased, and the activities of SOD, GSH-Px, and CAT were decreased in the LPS group, which were all reversed by treatment with $\mathrm{H}_{2} \mathrm{~S}$ (Figures 3(a)-3(e)). These results suggest that $\mathrm{H}_{2} \mathrm{~S}$ is able to abate LPS-induced oxidative stress in L6 cells. ROS are important and common messengers produced in various environmental stresses and are known to activate the MAPK pathway $[37,39,40]$. The MAPK family is composed of three major components: ERK, JNK, and p38 protein kinases [41, 42]. As shown in Figures 3(f)-3(h), LPS triggered phosphorylations of p38, JNK, and ERK with distinct patterns. However, treatment with $\mathrm{H}_{2} \mathrm{~S}$ decreased phosphorylations of these protein kinases. The results show that $\mathrm{H}_{2} \mathrm{~S}$ mediates the ROS/MAPK pathway in L6 cells.

3.4. $\mathrm{H}_{2} \mathrm{~S}$ Alleviates LPS-Induced Inflammation by Mediating the TLR4/Nuclear Factor-Kappa $B$ (NF- $\kappa B)$ Signaling Pathway in L6 Cells. Many studies have shown that treatment with LPS could induce increased expressions of inflammatory cytokines in L6 cells, such as MCP-1, TNF- $\alpha$, IL-6, and IL-10 [43-45]. Whether $\mathrm{H}_{2} \mathrm{~S}$ could reduce the levels of inflammation in LPS-treated L6 cells remains unknown. In this study, the inflammatory cytokine levels in L6 cells were determined using ELISA techniques. Compared with the control group, expression levels of MCP-1, TNF- $\alpha$, IL- $1 \beta$, IL-6, IL-10, and IL-18 were increased in the LPS group. Treatment with $\mathrm{H}_{2} \mathrm{~S}$ decreased the levels of these inflammatory cytokines (Figures $4(\mathrm{a})-4(\mathrm{f})$ ), suggesting that $\mathrm{H}_{2} \mathrm{~S}$ could 


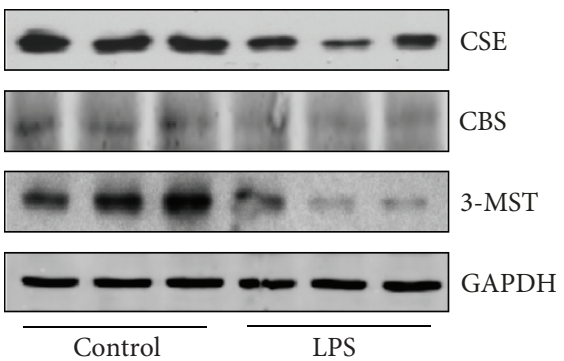

(a)

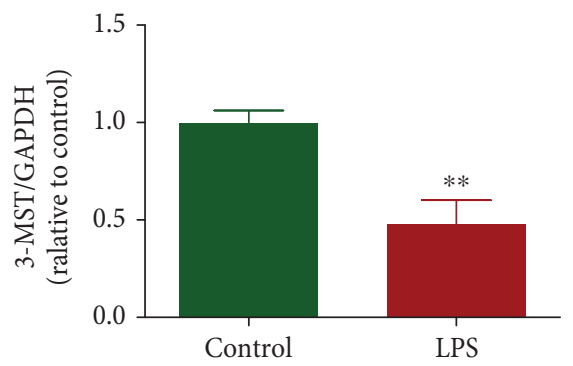

(d)
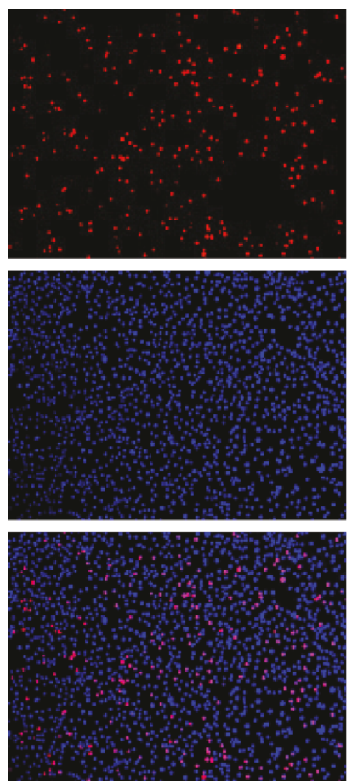

Control

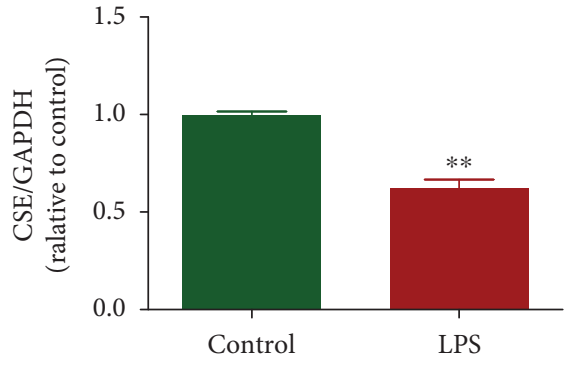

(b)

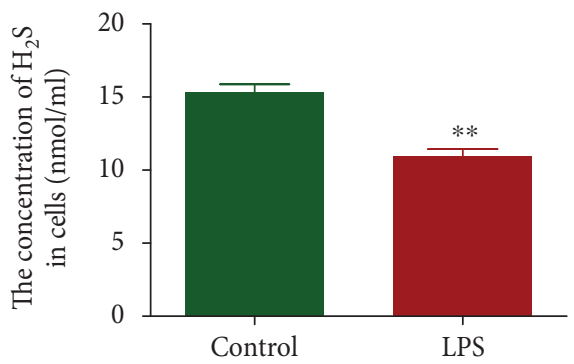

(e)
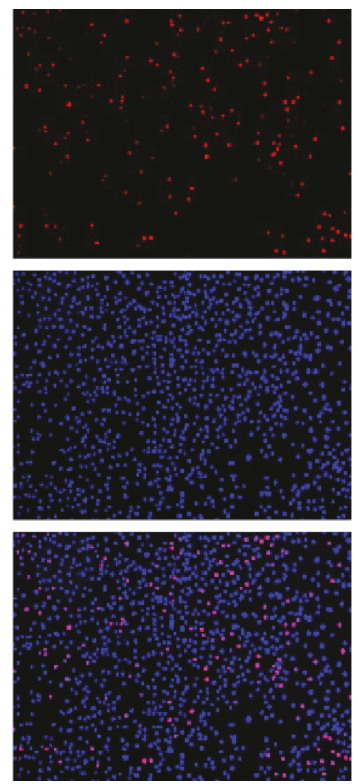

LPS

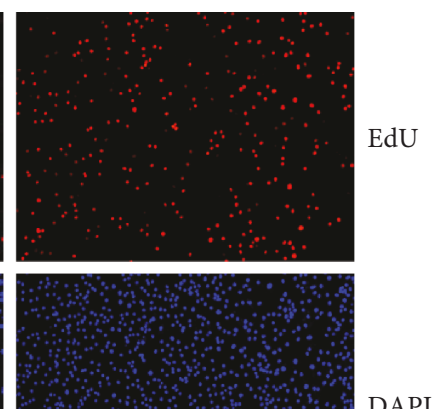

DAPI
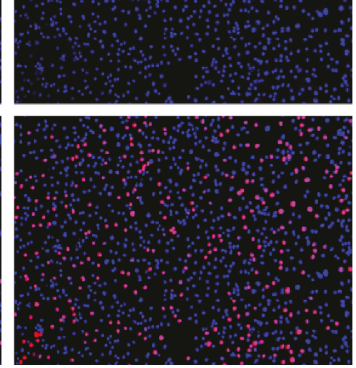

$\mathrm{LPS}+\mathrm{H}_{2} \mathrm{~S}$

(g)

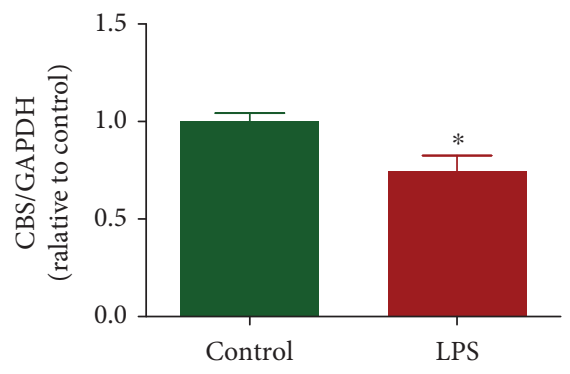

(c)

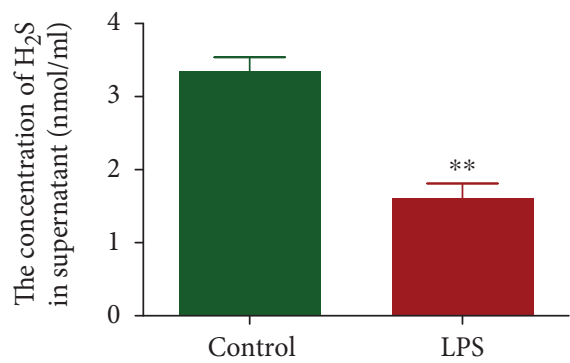

(f)

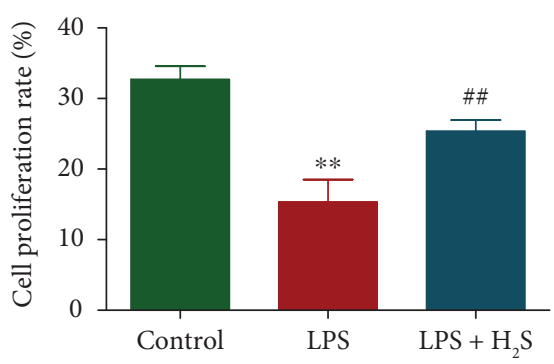

(h)

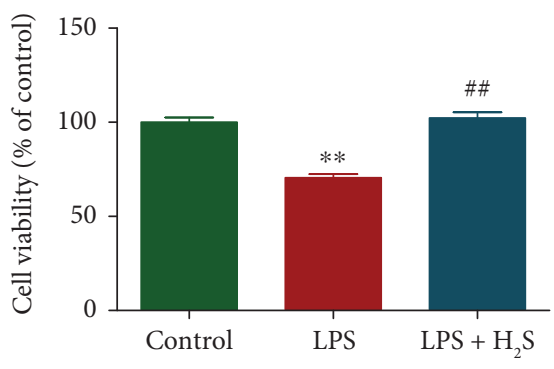

(i)

FIgUre 1: The levels of endogenous $\mathrm{H}_{2} \mathrm{~S}$ in L6 cells and LPS-treated L6 cells were detected, and the effects of exogenous $\mathrm{H}_{2} \mathrm{~S}$ on the growth of LPS-treated L6 cells were examined. (a) The protein expression of CSE, CBS, and 3-MST were examined by Western blot. GAPDH was used as the loading control. (b-d) Bar graphs showed the quantification of CSE, CBS, and 3-MST. The densitometry analysis of each factor was performed, normalized to the corresponding GAPDH level. (e) The levels of $\mathrm{H}_{2} \mathrm{~S}$ in L6 cells and LPS-treated L6 cells. (f) The levels of $\mathrm{H}_{2} \mathrm{~S}$ in the culture supernatant. (g) DNA replication activities were examined by EdU assay; original magnification, $\times 200$. (h) The proliferation rate of each group was analyzed. (i) The percentages of viable cells were determined using the MTT assay, and the cell viability of L6 cells was normalized as $100 \%$ and considered to be the control group. Data are presented as mean \pm SEM of three independent experiments; ${ }^{*} P$ $<0.05$ and ${ }^{* *} P<0.01$ compared with the control group; ${ }^{\#} P<0.01$ compared with the LPS group.

alleviate inflammation in LPS-treated L6 cells. TLR4, a type I transmembrane receptor, plays an important role in the innate immune system. It is widely accepted that LPS can activate the TLR4/NF- $\kappa \mathrm{B}$ signaling pathway $[46,47]$. In the present study, we found that LPS increased the expression of TLR4, which was reduced by $\mathrm{H}_{2} \mathrm{~S}$ treatment (Figure $4(\mathrm{~g})$ ). TAK1, IKK, and $\mathrm{I} \kappa \mathrm{B}$ are key upstream modulators for NF- $\kappa \mathrm{B}$ activation [48]. As shown in Figures $4(\mathrm{~h})-4(\mathrm{j})$, LPS treatment increased levels of phosphorylated TAK1, IKK $\alpha / \beta$, and $\mathrm{I} \kappa \mathrm{B} \alpha$. However, these effects were reversed by treatment with $\mathrm{H}_{2} \mathrm{~S}$. The most abundant form of NF- $\kappa \mathrm{B}$ is the heterodimer 


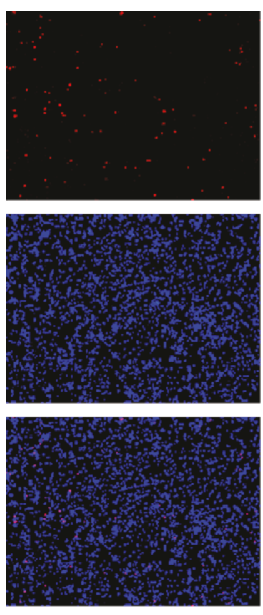

Control
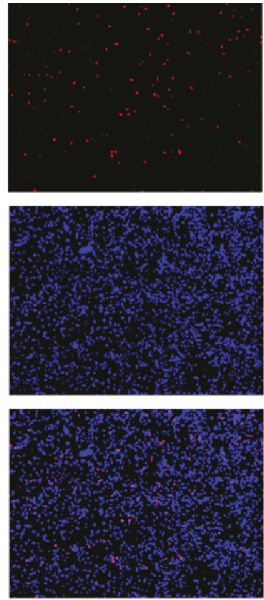

LPS
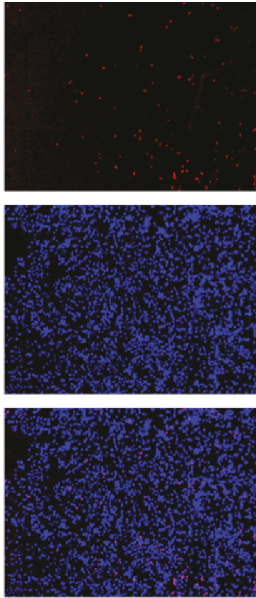

LPS $+\mathrm{H}_{2} \mathrm{~S}$

(a)

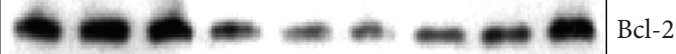

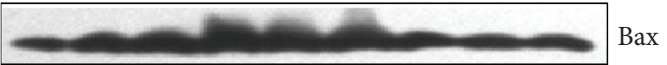

$\square 000000 \mathrm{Bcl-xl}$
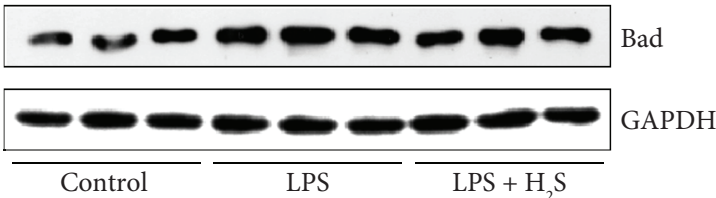

(c)

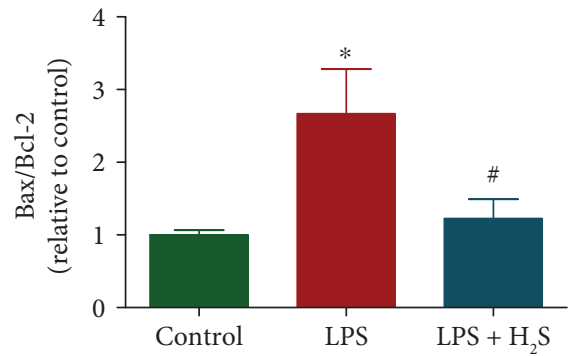

(e)

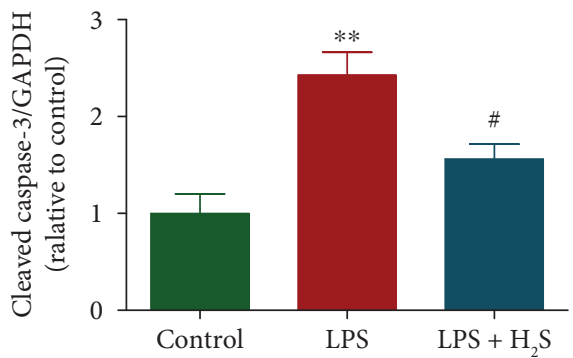

(g)

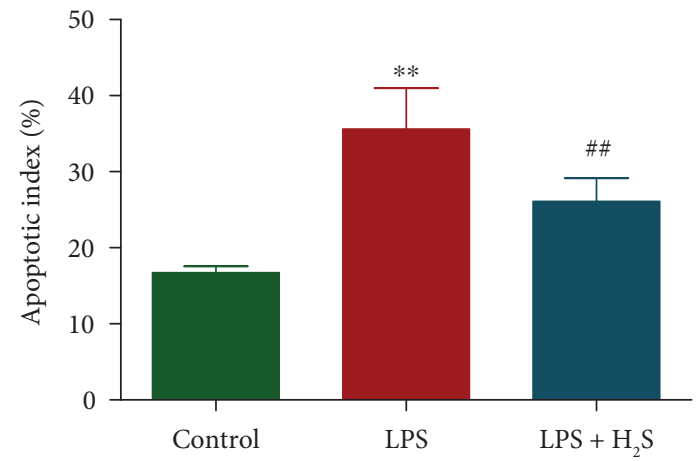

(b)

$=-m=-m-m$ Cleaved caspase-3 $-\infty-\infty-\infty-1$ Cleaved caspase-8 $0-\infty \infty \infty-\infty$ Cleaved caspase-9

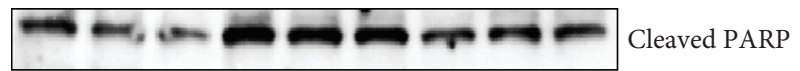

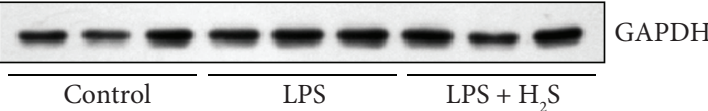

(d)

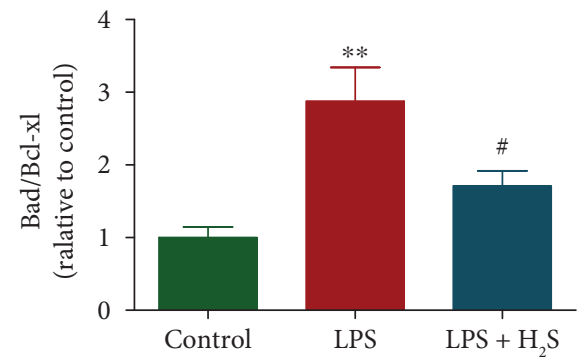

(f)

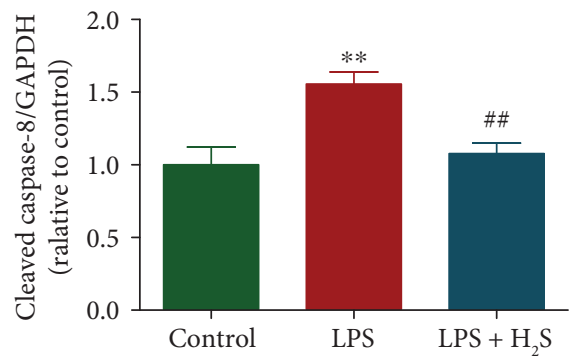

(h)

Figure 2: Continued. 


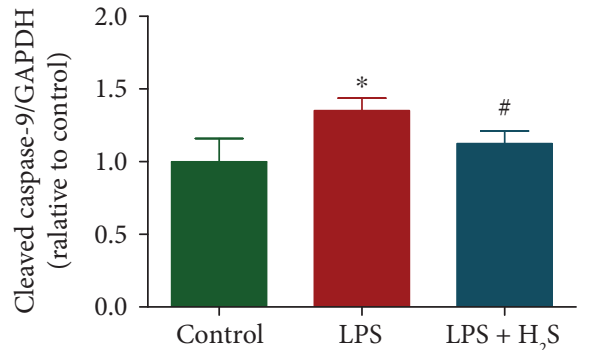

(i)

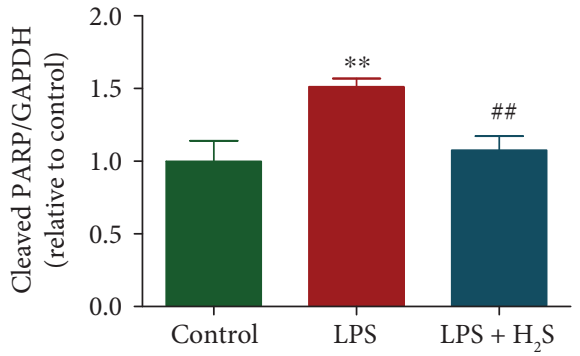

(j)

FIgURE 2: Effects of $\mathrm{H}_{2} \mathrm{~S}$ on the apoptosis of LPS-treated L6 cells. (a) The apoptotic levels were measured by TUNEL staining; original magnification, $\times 100$. (b) The percentages of TUNEL-positive cells were calculated by the formula: the apoptotic index $=$ (positively stained apoptotic cells)/(total number of cells) $\times 100 \%$. (c-d) Western blotting analysis for the expression levels of Bcl-2, Bax, Bcl-xl, and Bad, cleaved caspase-3, -8 , and -9 and cleaved PARP in each group. GAPDH was used as the loading control. (e-j) The densitometry analysis of each factor was performed in each group, normalized to the corresponding GAPDH level. Data are presented as mean \pm SEM of three independent experiments; ${ }^{*} P<0.05$ and ${ }^{* *} P<0.01$ compared with the control group; ${ }^{\#} P<0.05$ and ${ }^{\# \# P}<0.01$ compared with the LPS group.

composed of p50 and p65 [49]. Compared with the control group, LPS treatment increased protein expressions of p50 and p-p65 and the p-p65/p65 ratio. Administration of $\mathrm{H}_{2} \mathrm{~S}$ decreased expression levels of p50 and p-p65, as well as the ratio of p-p65/p65 (Figures 4(k) and 4(l)). These results together indicate that $\mathrm{H}_{2} \mathrm{~S}$ is capable of reducing LPS-induced inflammation through inhibition of the TLR4/NF- $\kappa \mathrm{B}$ signaling pathway.

3.5. $\mathrm{H}_{2} \mathrm{~S}$ Improves Diaphragmatic Function and Structure of Septic Rats. There was no significant difference in body weight at the beginning of the animal study. After $24 \mathrm{~h}$, LPS treatment reduced the body weights of the rats, while $\mathrm{H}_{2} \mathrm{~S}$ increased the body weights of septic rats (Figure 5(a)). However, there was no significant difference in strip weight among each group (Figure 5(b)). LPS elicited a large reduction in the force-generating capacity of the diaphragm, producing dramatic reductions in musclespecific force generation of the diaphragm. Administration of $\mathrm{H}_{2} \mathrm{~S}$ attenuated the effects of LPS on diaphragm strength, with force generation at the stimulation frequencies from 20 to $100 \mathrm{~Hz}$ (Figure 5(c)). As shown in Figures 5(d) and 5(e), LPS decreased both maximum tetanic tension and peak twitch tension, whereas the effects were reversed by treatment with $\mathrm{H}_{2} \mathrm{~S}$. In addition, LPS reduced the fatigue index, which was enhanced by $\mathrm{H}_{2} \mathrm{~S}$ treatment (Figure 5(f)). Furthermore, LPS decreased the maximal rates of contraction and relaxation $\left( \pm d T / d t_{\max }\right)$, while $\mathrm{H}_{2} \mathrm{~S}$ increased the maximal rates of contraction/relaxation (Figures $5(\mathrm{~g})$ and 5(h)). As shown in Figures 5(i)-5(k), the CSA of both $\mathrm{MHC}_{\text {fast }}$ and $\mathrm{MHC}_{\text {slow }}$ was decreased in the LPS group. However, administration of $\mathrm{H}_{2} \mathrm{~S}$ prevented the loss of the CSA of $\mathrm{MHC}_{\text {fast }}$ and $\mathrm{MHC}_{\text {slow }}$ compared with the LPS group, indicating that $\mathrm{H}_{2} \mathrm{~S}$ can reduce LPS-induced diaphragm injury. Collectively, these data demonstrate that $\mathrm{H}_{2} \mathrm{~S}$ improves diaphragmatic function and structure of septic rats.

3.6. $\mathrm{H}_{2} \mathrm{~S}$ Decreases Inflammation and Apoptosis in the Diaphragm of Septic Rats. The expressions of cytokine genes were detected by qRT-PCR. As shown in Figures 6(a)-6(f), gene expressions of MCP-1, TNF- $\alpha$, IL- $1 \beta$, IL-6, IL-10, and IL-18 were increased in the LPS group. Treatment with $\mathrm{H}_{2} \mathrm{~S}$ decreased gene expressions of these inflammatory cytokines. IHC with the Ki67 antibody confirmed that the in vivo proliferation of diaphragmatic muscle cells was inhibited in the LPS group and promoted in the LPS $+\mathrm{H}_{2} \mathrm{~S}$ group (Figures $6(\mathrm{~g})$ and $6(\mathrm{~h})$ ). However, the protein expression of cleaved caspase-3 exhibited an opposite trend (Figures 6(g) and 6(i)). These results together indicate that $\mathrm{H}_{2} \mathrm{~S}$ is able to decrease inflammation and apoptosis in the diaphragm of septic rats.

\section{Discussion}

$\mathrm{H}_{2} \mathrm{~S}$ has been considered the third gaseous signaling molecule and plays important roles in a wide range of physiological and pathological conditions $[13,16,18]$. However, the effect and mechanism of $\mathrm{H}_{2} \mathrm{~S}$ in diaphragm dysfunction have not been fully elucidated. Rat skeletal muscle cell line L6 has been widely used to study the regeneration and function of skeletal muscle [50-52]. LPS, a major constituent of the cell wall of Gram-negative bacteria, is a potent agent widely used to model bacterial challenges of mammalian cells $[27,28]$. In the present study, L6 cells were used to evaluate the effects of $\mathrm{H}_{2} \mathrm{~S}$ on the LPS-induced diaphragmatic injury in vitro. The results demonstrated that the protein levels of $\mathrm{H}_{2} \mathrm{~S}$-generating enzymes and the levels of $\mathrm{H}_{2} \mathrm{~S}$ in LPS-treated L6 cells and supernatant were lower than those in L6 cells and the supernatant, suggesting that $\mathrm{H}_{2} \mathrm{~S}$ may be involved in the growth of L6 cells. To test this hypothesis, we examined the effect of exogenous $\mathrm{H}_{2} \mathrm{~S}$ on the growth of LPS-treated L6 cells. The results showed that the proliferation and viability of L6 cells were inhibited in the LPS group, whereas administration of $\mathrm{H}_{2} \mathrm{~S}$ enhanced the proliferation and viability of LPS-treated $\mathrm{L} 6$ cells, indicating that $\mathrm{H}_{2} \mathrm{~S}$ is involved in the growth of L6 cells.

Apoptosis is a highly regulated mechanism of cell death which plays a critical role in the normal development and maintenance of tissue homeostasis in multicellular organisms [53]. There are two main apoptotic signaling pathways: 


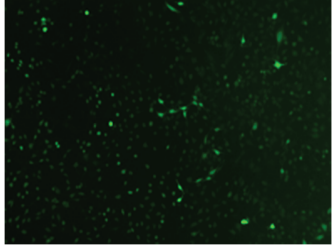

Control

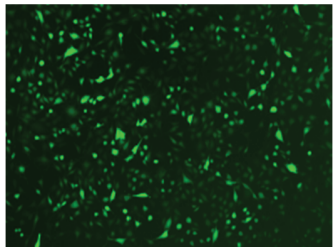

LPS

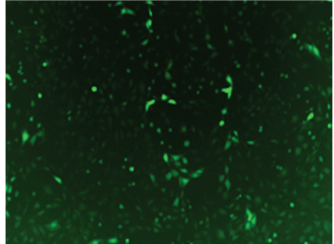

$\mathrm{LPS}+\mathrm{H}_{2} \mathrm{~S}$

(a)

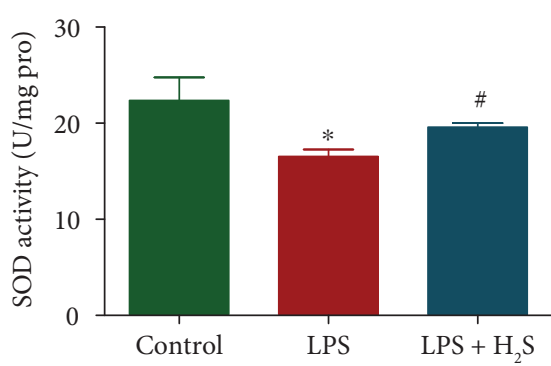

(c)
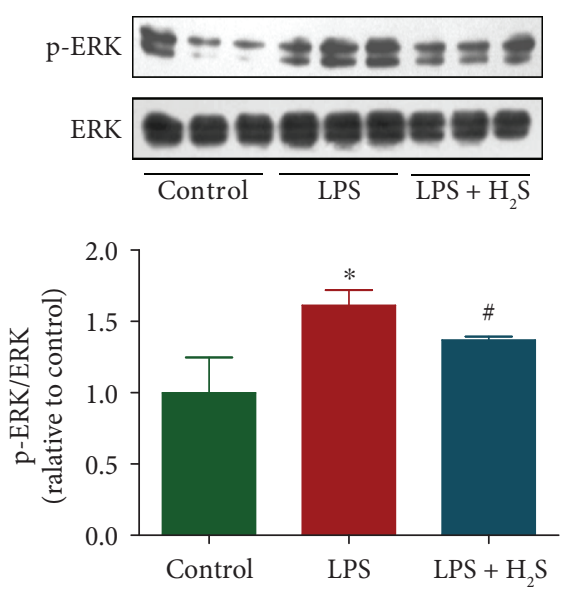

(f)

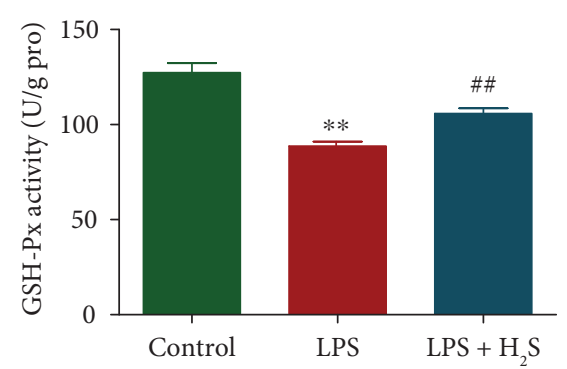

(d)
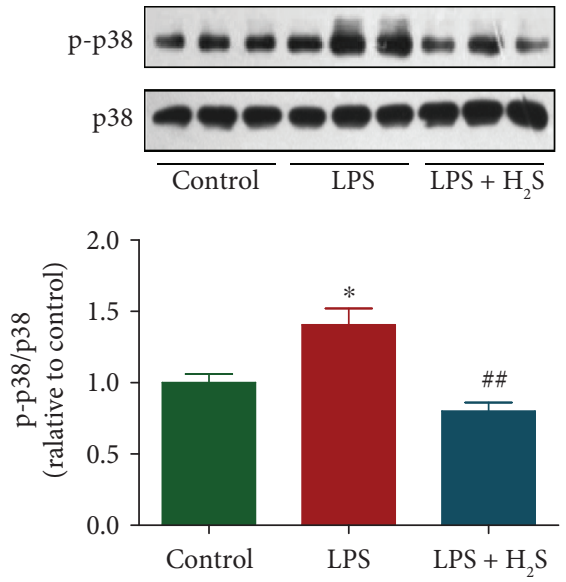

(g)

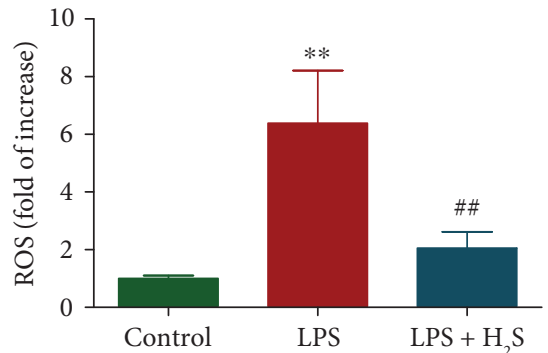

(b)

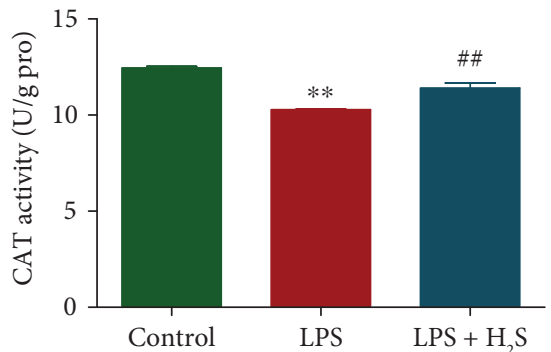

(e)
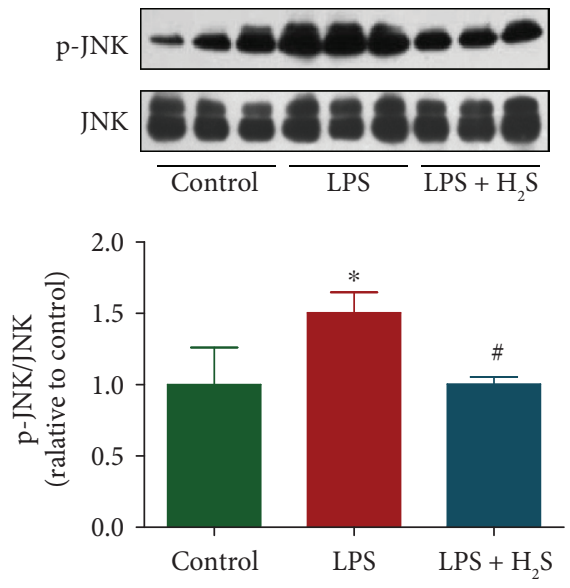

(h)

FIGURE 3: Effects of $\mathrm{H}_{2} \mathrm{~S}$ on the ROS/MAPK signaling pathway in LPS-treated L6 cells. (a) The intracellular ROS production was detected using the fluorescent probe DCF-DA (shown in green; original magnification, $\times 100$ ). (b) The intracellular ROS production was measured. (c-e) The activities of SOD, GSH-Px, and CAT were measured. (f-h) The protein expressions of ERK1/2, p-ERK1/2, p38, p-p38, JNK, and p-JNK were analyzed by Western blotting. Data are presented as mean \pm SEM of three independent experiments; ${ }^{*} P<0.05$ and ${ }^{* *} P<0.01$ compared with the control group; ${ }^{\#} P<0.05$ and ${ }^{\# \#} P<0.01$ compared with the LPS group.

an extrinsic pathway initiated by death receptors and an intrinsic pathway that occurs through the mitochondria [54]. Apoptosis is regulated by Bcl-2 family proteins, including proapoptotic proteins such as Bax and Bad, and antiapoptotic proteins such as $\mathrm{Bcl}-2$ and $\mathrm{Bcl}-\mathrm{xl}$ [55]. Caspases can be activated by apoptotic stimuli and cleaved caspase- 3 can inactivate PARP, thus leading to the occurrence of apoptotic cascade [56]. Recent studies have shown that LPS could induce apoptosis in different types of cells $[28,57$, 58]. Similarly, our results indicated that LPS increased the apoptotic index, $\mathrm{Bax} / \mathrm{Bcl}-2$ and $\mathrm{Bad} / \mathrm{Bcl}-\mathrm{xl}$ ratios, as well as protein expression levels of cleaved caspase-3, -8 , and -9 and cleaved PARP in L6 cells. Treatment with $\mathrm{H}_{2} \mathrm{~S}$ decreased the apoptotic level in the LPS group. In sum, these results demonstrate that the apoptotic level in LPS-treated L6 cells is increased and administration of $\mathrm{H}_{2} \mathrm{~S}$ can reduce the apoptotic level.

High levels of ROS could lead to an imbalance of the cellular redox state and oxidative stress, as well as induce cell apoptosis or necrosis in a number of physiological and pathological conditions $[59,60]$. Our results demonstrated that LPS increased the levels of ROS and decreased the activities of SOD, GSH-Px, and CAT, which were similar to a previous study [61]. All these changes were reversed by treatment with $\mathrm{H}_{2} \mathrm{~S}$. It has been shown that ROS could activate MAPKs, and apoptotic cell death induced by ROS is mediated by the MAPK pathway [62]. The MAPK family is mainly composed of three components, including ERK, JNK, and p38 protein kinases [41, 42]. Recently, it has been demonstrated that LPS is able to decrease the protein synthetic rate in $\mathrm{C} 2 \mathrm{C} 12$ 


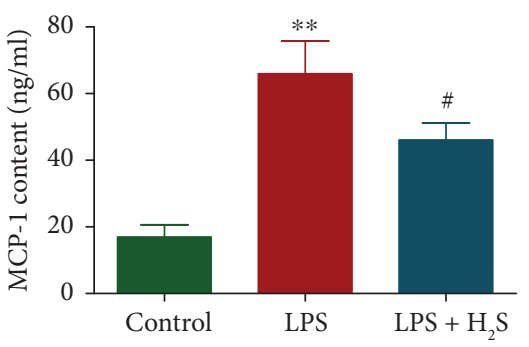

(a)

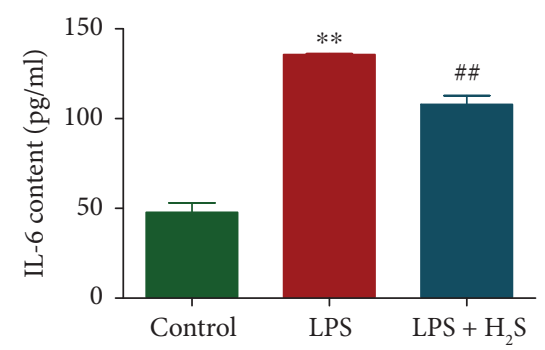

(d)
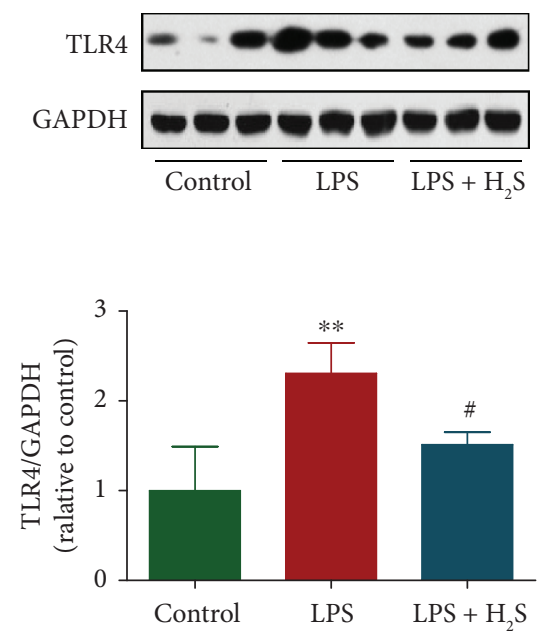

(g)
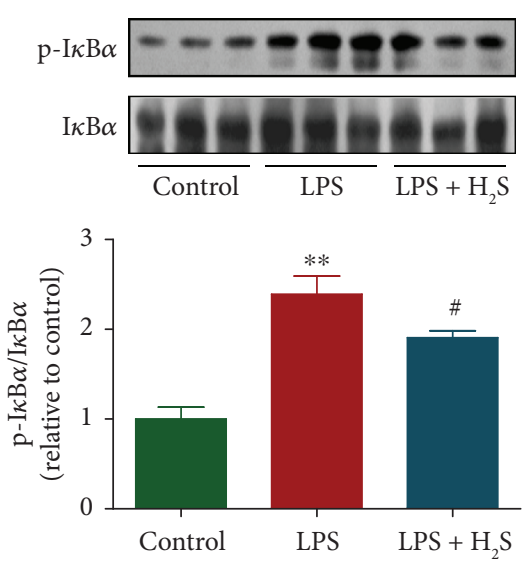

(j)

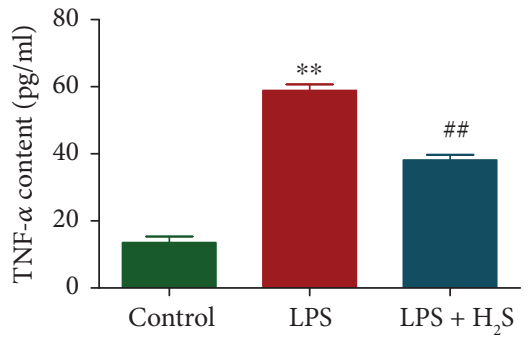

(b)

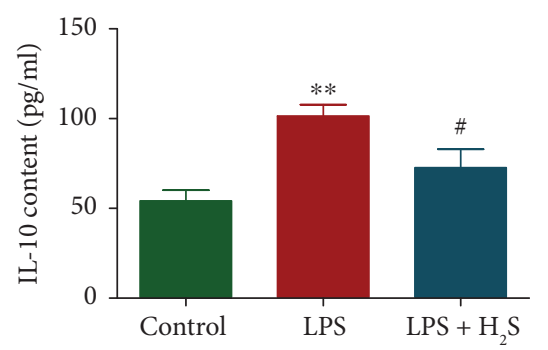

(e)
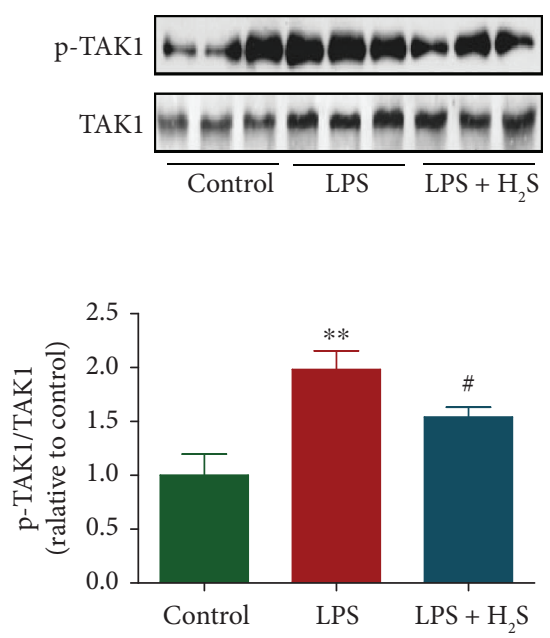

(h)
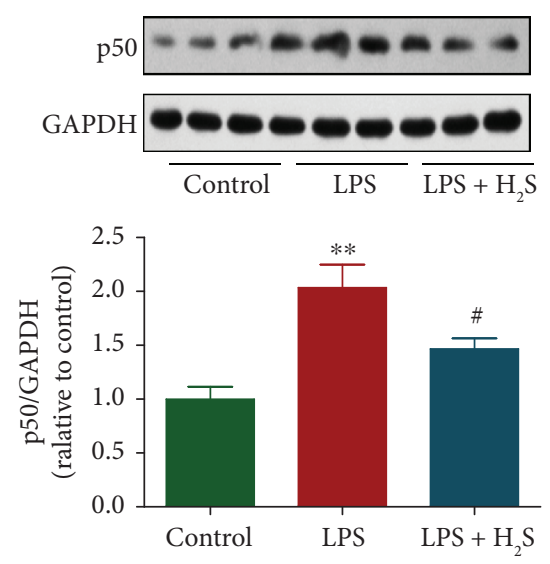

(k)

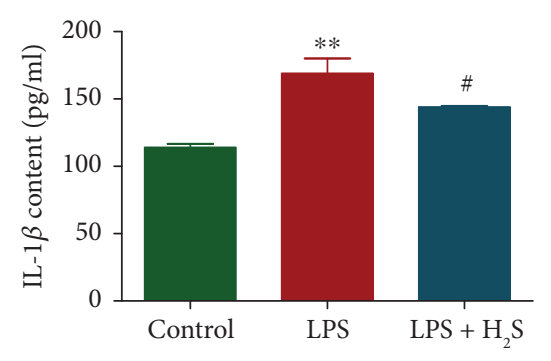

(c)

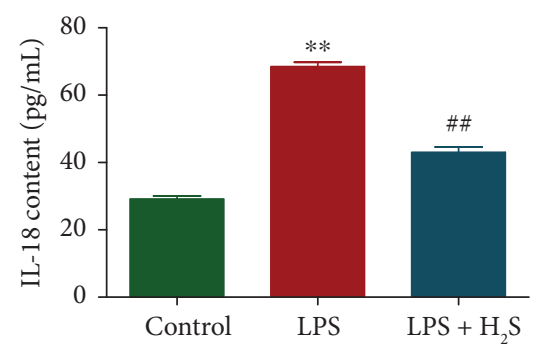

(f)
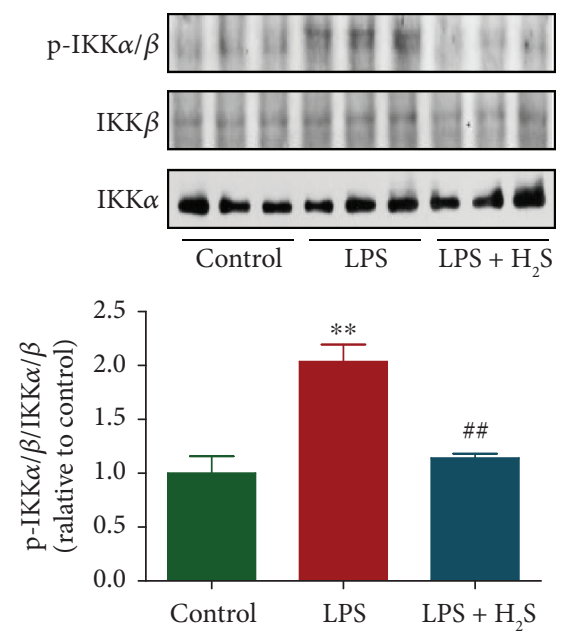

(i)
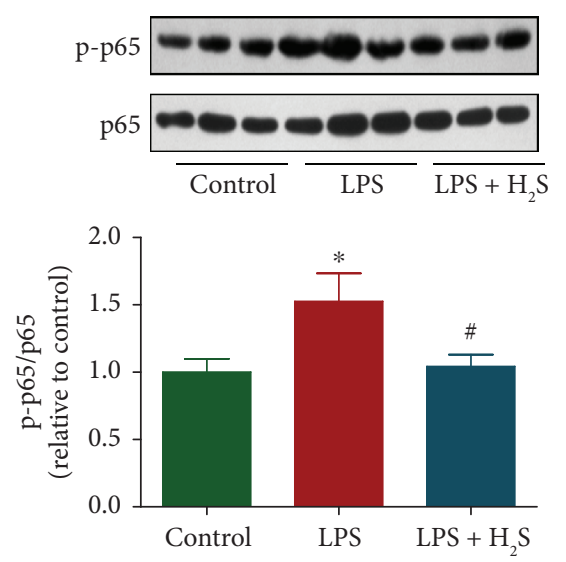

(1)

FIGURE 4: Effects of $\mathrm{H}_{2} \mathrm{~S}$ on the cytokine levels and the TLR4/NF- $\kappa \mathrm{B}$ signaling pathway in diaphragmatic muscle tissues of septic rats. (a-f) The expression levels of MCP-1, TNF- $\alpha$, IL-1 $\beta$, IL-6, IL-10, and IL-18 were measured. (g-l) The protein expressions of TLR4, TAK1, p-TAK1, $\mathrm{IKK} \alpha, \mathrm{IKK} \beta, \mathrm{p}-\mathrm{IKK} \alpha / \beta, \mathrm{I} \kappa \mathrm{B} \alpha, \mathrm{p}-\mathrm{I} \kappa \mathrm{B} \alpha, \mathrm{p} 50, \mathrm{p} 65, \mathrm{p}-\mathrm{p} 65$, and GAPDH were analyzed by Western blotting. Data are presented as mean $\pm \mathrm{SEM}$ of three independent experiments; ${ }^{*} P<0.05$ and ${ }^{* *} P<0.01$ compared with the control group; $P<0.05$ and ${ }^{\# \#} P<0.01$ compared with the LPS group. 


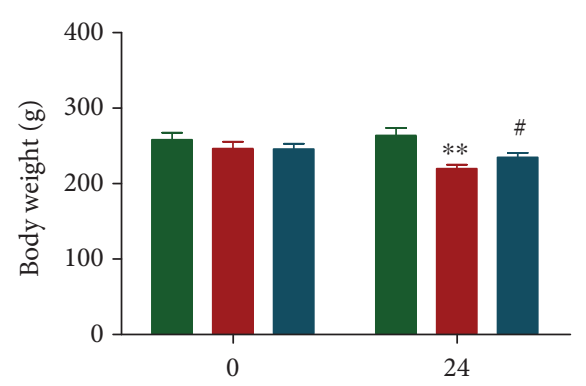

(h)

Control

LPS

LPS $+\mathrm{H}_{2} \mathrm{~S}$

(a)

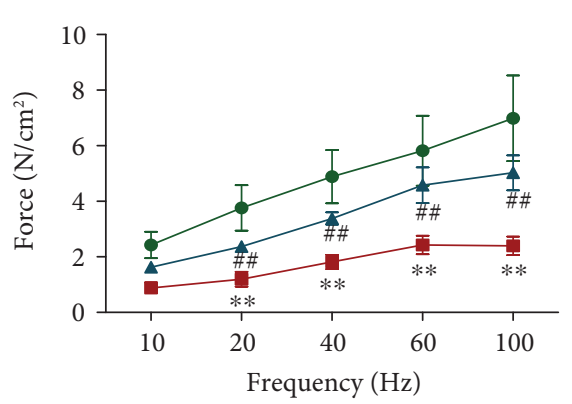

$\rightarrow$ Control

$\rightarrow$ LPS

$\rightarrow$ LPS $+\mathrm{H}_{2} \mathrm{~S}$

(c)

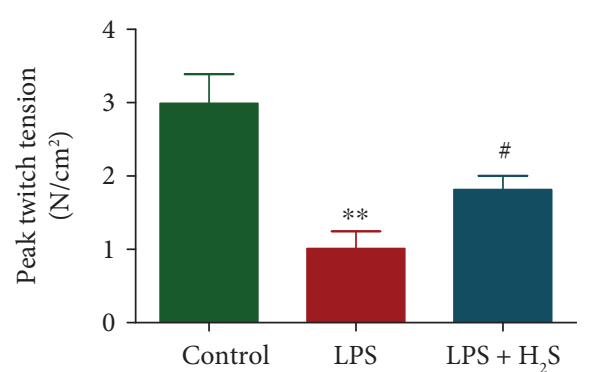

(e)

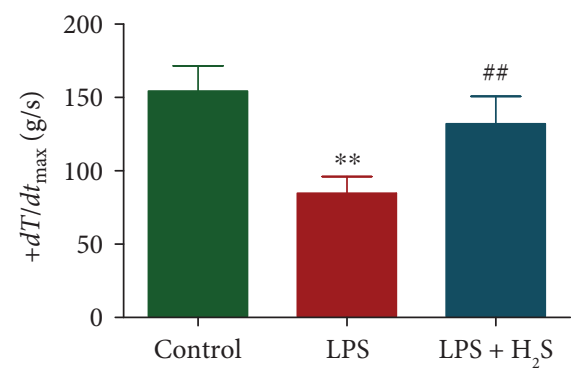

(g)

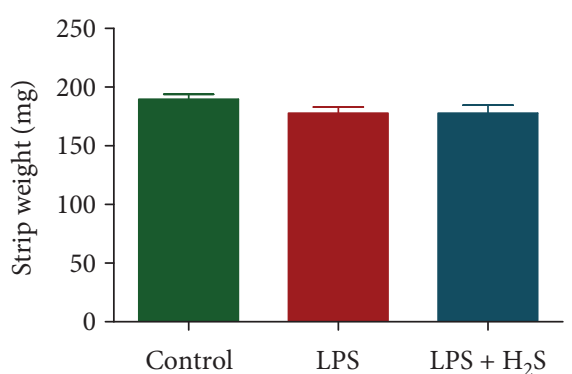

(b)

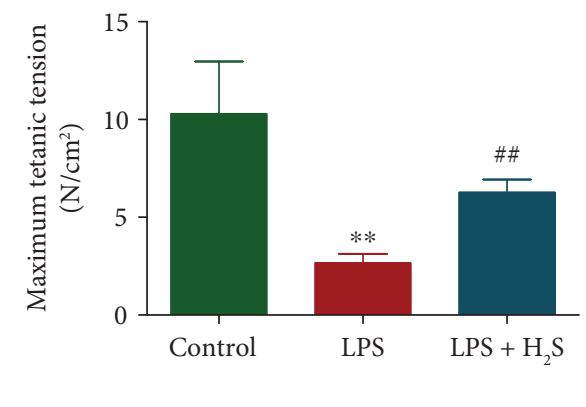

(d)

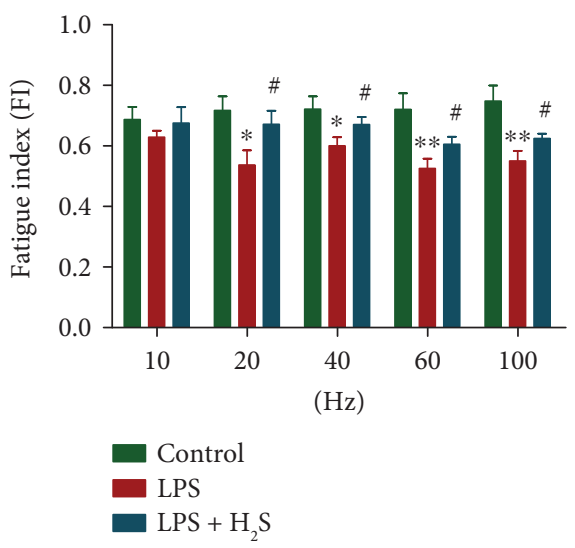

(f)

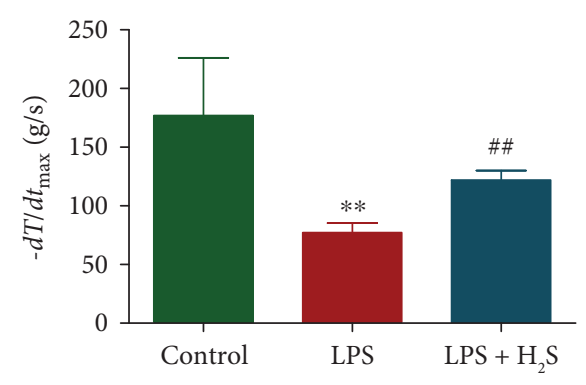

(h)

Figure 5: Continued. 

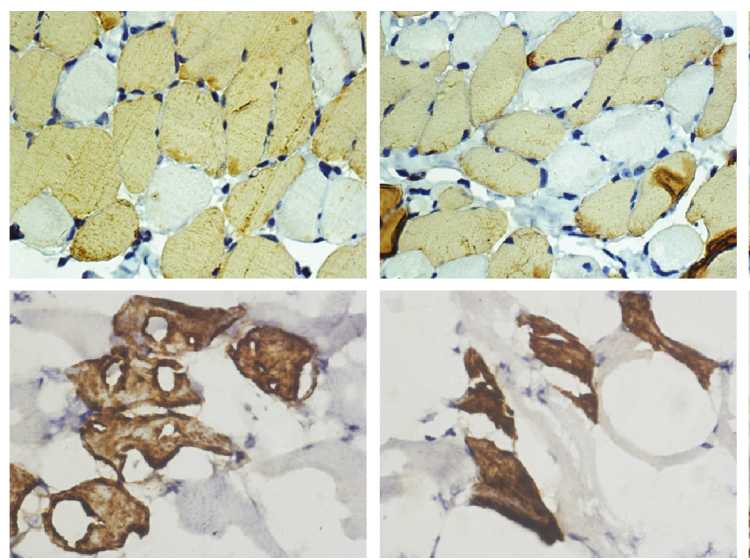

(i)

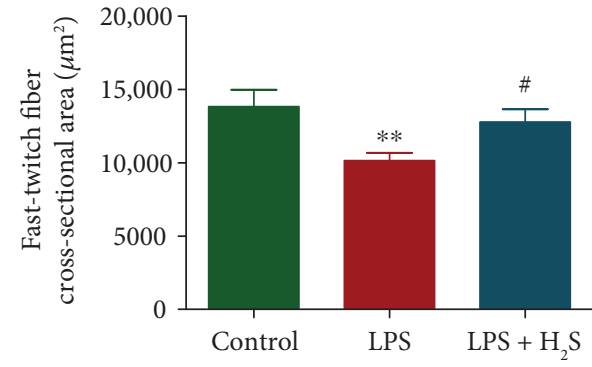

(j)

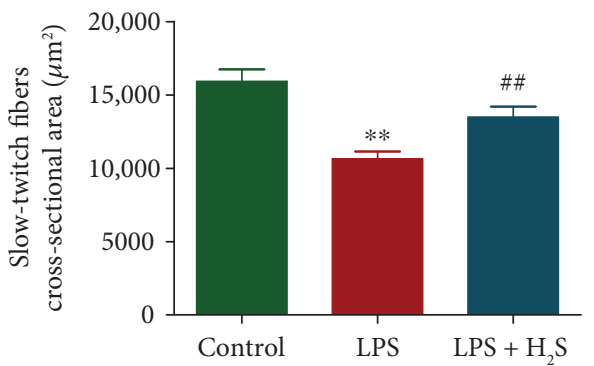

(k)

Figure 5: Effects of $\mathrm{H}_{2} \mathrm{~S}$ on the diaphragmatic function and structure of septic rats. $(\mathrm{a}, \mathrm{b})$ The body weight and strip weight of rats were measured. (c) The contractile force was measured. (d, e) The maximum tetanic tension and peak twitch tension were detected. (f) The fatigue index was measured. $(\mathrm{g}, \mathrm{h})$ The maximal rate of contraction $\left(+d T / d t_{\max }\right)$ and the maximal rate of relaxation $\left(-d T / d t_{\max }\right)$ were detected. (i) Representative photographs of diaphragm muscle cross-sectional area in diaphragm skeletal muscle myofibers of rats; original magnification, $\times 400$. (j, k) Fast-twitch fibers and slow-twitch fibers were calculated. Values were presented as mean \pm SEM $(n=6) .{ }^{*} P<0.05$ and ${ }^{* *} P<0.01$ compared with the control group; ${ }^{*} P<0.05$ and ${ }^{\# \#} P<0.01$ compared with the LPS group.

mouse myoblasts through P38/ERK1/2 activation [63]. Furthermore, JNK and p38 can be phosphorylated in LPS-induced inflammatory responses in L6 myoblasts [44]. In line with the above findings, our results showed that LPS triggered the phosphorylations of p38, JNK, and ERK with distinct patterns. However, $\mathrm{H}_{2} \mathrm{~S}$ decreased the phosphorylations of these protein kinases. These results together suggest that $\mathrm{H}_{2} \mathrm{~S}$ can decrease ROS-induced apoptosis through the MAPK signaling pathway in LPStreated L6 cells.

It has been shown that LPS could increase expressions of inflammatory cytokines in L6 cells, such as TNF- $\alpha$, MCP-1, IL-6, and IL-10 [43-45]. In the present study, LPS treatment increased the expression levels of MCP-1, TNF- $\alpha$, IL-1 $\beta$, IL-6, IL-10, and IL-18. $\mathrm{H}_{2} \mathrm{~S}$ treatment decreased the levels of these inflammatory cytokines, indicating that $\mathrm{H}_{2} \mathrm{~S}$ is capable of alleviating inflammation in LPS-treated L6 cells. TLR4, a main receptor of LPS, plays a key role in the initiation and acceleration of inflammatory responses induced by LPS $[64,65]$. Activation of TLR4 by LPS can induce the activation of the NF- $\kappa \mathrm{B}$ signaling pathway to regulate the release of proinflammatory cytokines [46, 47]. Our results showed that LPS increased the expressions of TLR4, p-TAK1, p-IKK $\alpha / \beta, \quad \mathrm{p}-\mathrm{I} \kappa \mathrm{B} \alpha, \mathrm{p} 50$, and $\mathrm{p}-\mathrm{p} 65$. However, these effects were reversed by treatment with
$\mathrm{H}_{2} \mathrm{~S}$, suggesting that $\mathrm{H}_{2} \mathrm{~S}$ is able to reduce LPS-induced inflammation by suppressing the TLR $4 / \mathrm{NF}-\kappa \mathrm{B}$ signaling pathway in L6 cells.

Recent studies have demonstrated that administration of LPS can induce diaphragmatic contractile dysfunction in several animal models [24, 27, 29]. Our results indicated that LPS treatment reduced the force-generating capacity, maximum tetanic tension, peak twitch tension, fatigue index, and the maximal rates of contraction and relaxation of the diaphragm of septic rats. Administration of $\mathrm{H}_{2} \mathrm{~S}$ improved the impaired diaphragmatic function induced by LPS in septic rats. In addition, a recent study has shown that LPS treatment decreases the CSA of embryonic MHC fibers in the preterm diaphragm of pregnant ewes [66]. Our results showed that LPS decreased the CSA of both $\mathrm{MHC}_{\text {slow }}$ and $\mathrm{MHC}_{\text {fast }}$, while $\mathrm{H}_{2} \mathrm{~S}$ prevented LPS-induced loss of CSA of $\mathrm{MHC}_{\text {slow }}$ and $\mathrm{MHC}_{\text {fast }}$ in the diaphragm of septic rats. Furthermore, $\mathrm{H}_{2} \mathrm{~S}$ decreased levels of inflammation and apoptosis induced by LPS in the diaphragm of septic rats. These data together indicate that $\mathrm{H}_{2} \mathrm{~S}$ is capable of improving diaphragmatic function and structure through reduction of inflammation and apoptosis in the diaphragm of septic rats.

In conclusion, our results demonstrate that $\mathrm{H}_{2} \mathrm{~S}$ is able to ameliorate LPS-induced diaphragm dysfunction in rats by reducing apoptosis and inflammation through ROS/MAPK 


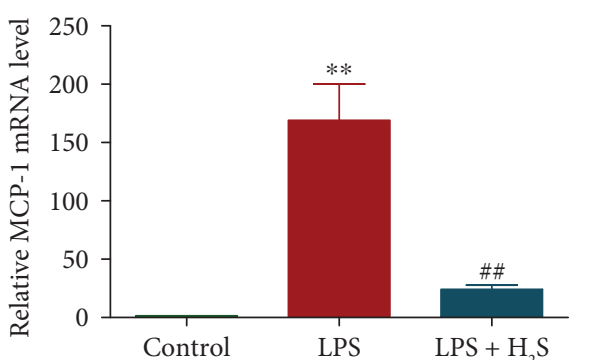

(a)

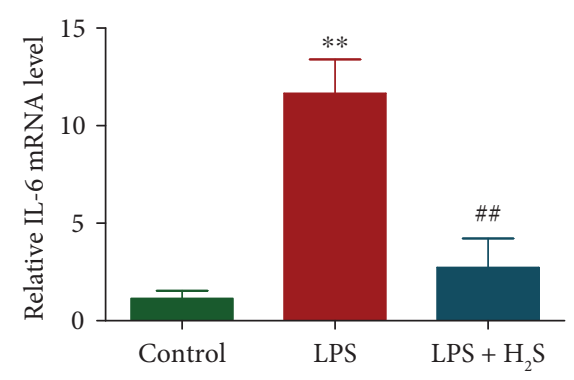

(d)

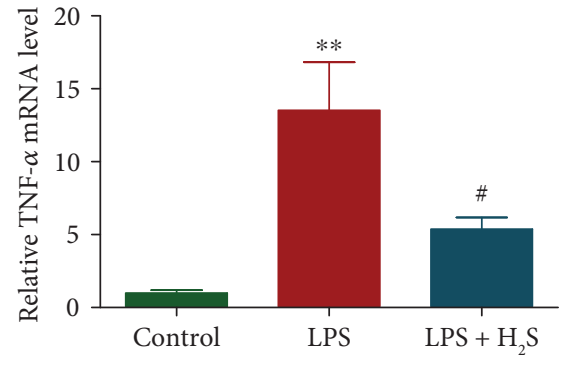

(b)

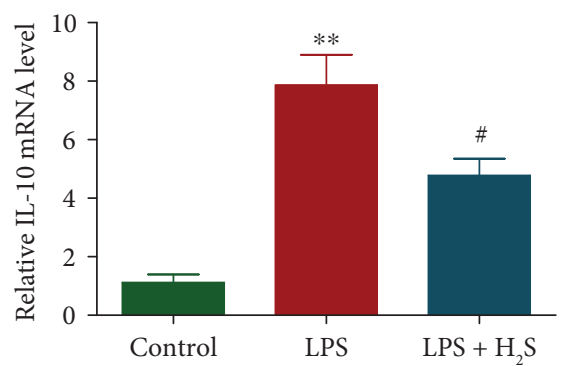

(e)

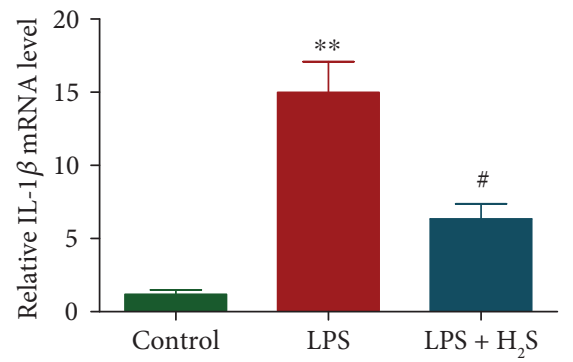

(c)

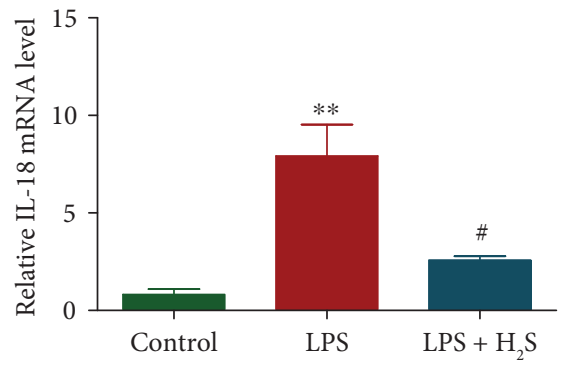

(f)
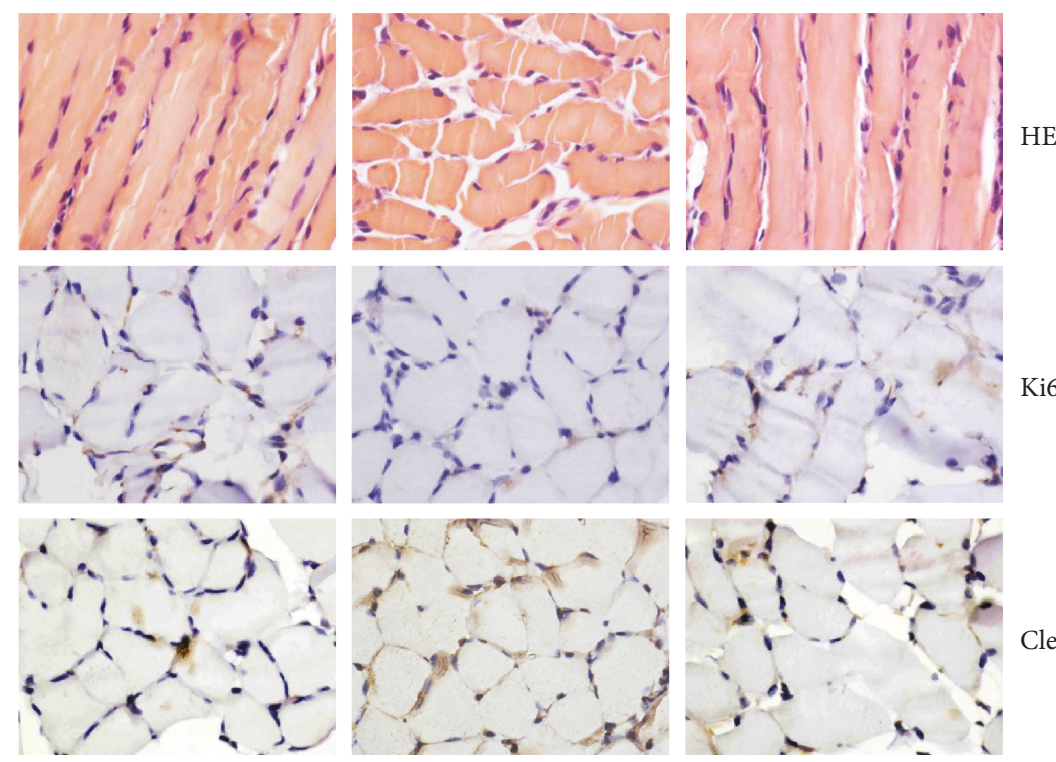

HE

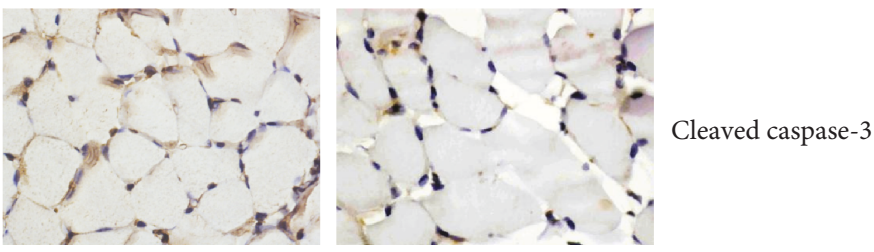

(g)

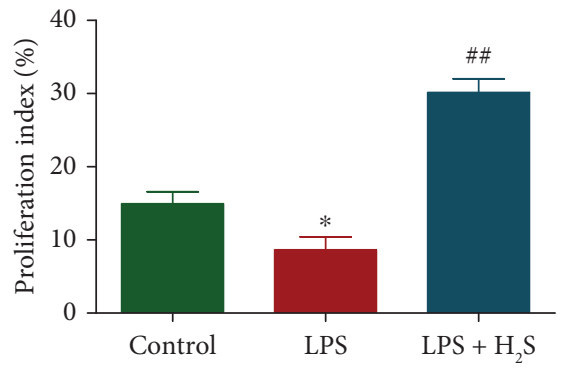

(h)

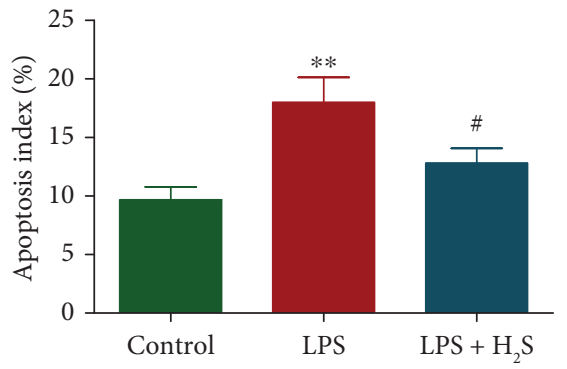

(i)

FIGURE 6: Effects of $\mathrm{H}_{2} \mathrm{~S}$ on the inflammation, proliferation, and apoptosis in the diaphragm of septic rats. (a-f) The expressions of MCP-1, TNF- $\alpha$, IL- $1 \beta$, IL-6, IL-10, and IL-18 were detected by qRT-PCR. Data are presented as mean \pm SEM of three independent experiments. (g) Representative photographs of HE, Ki67, and cleaved caspase-3 staining in the diaphragm of rats; original magnification, $\times 400$. (h, i) The proliferation index and apoptosis index were calculated. Values were presented as mean \pm SEM $(n=6)$. ${ }^{*} P<0.05$ and ${ }^{* *} P<0.01$ compared with the control group; ${ }^{\#} P<0.05$ and ${ }^{\# \#} P<0.01$ compared with the LPS group. 
and TLR4/NF- $\kappa \mathrm{B}$ signaling pathways. Novel slow-releasing $\mathrm{H}_{2} \mathrm{~S}$ donors can be designed and applied for the treatment of diaphragm dysfunction.

\section{Data Availability}

The raw data used to support the findings of this study are available from the corresponding author upon request.

\section{Conflicts of Interest}

The authors declare that they have no conflicts of interest related to this work.

\section{Authors' Contributions}

Guo-Yu Zhang, Dan Lu, and Shao-Feng Duan contributed equally to this work.

\section{Acknowledgments}

This work was supported by grants from the National Natural Science Foundation of China (no. U1504817 to Dong-Dong $\mathrm{Wu}$ and no. 81670088 to Xin-Ying Ji), the Foundation of Science \& Technology Department of Henan Province, China (no. 182102310335 to Dong-Dong Wu and no. 172102410019 to Xin-Ying Ji), the Natural Science Foundation of Education Department of Henan Province, China (no. 15A310017 to Dong-Dong Wu), and the Science Foundation of Henan University, China (nos. yqpy20170044 and 16NB048 to Dong-Dong Wu).

\section{References}

[1] G. L. Coles and K. G. Ackerman, "Kif7 is required for the patterning and differentiation of the diaphragm in a model of syndromic congenital diaphragmatic hernia," Proceedings of the National Academy of Sciences of the United States of America, vol. 110, no. 21, pp. E1898-E1905, 2013.

[2] B. Ahn, P. D. Coblentz, A. W. Beharry et al., "Diaphragm abnormalities in patients with end-stage heart failure: NADPH oxidase upregulation and protein oxidation," Frontiers in Physiology, vol. 7, p. 686, 2017.

[3] S. Tuncer, N. Dalkilic, and I. Burat, "Electrophysiological alterations in diaphragm muscle caused by abdominal ischemia-reperfusion," Respiratory Physiology \& Neurobiology, vol. 238, pp. 7-13, 2017.

[4] A. Faisal, B. J. Alghamdi, C. E. Ciavaglia et al., "Common mechanisms of dyspnea in chronic interstitial and obstructive lung disorders," American Journal of Respiratory and Critical Care Medicine, vol. 193, no. 3, pp. 299-309, 2016.

[5] E. Barreiro and J. Gea, "Epigenetics and muscle dysfunction in chronic obstructive pulmonary disease," Translational Research, vol. 165, no. 1, pp. 61-73, 2015.

[6] R. C. Kelley and L. F. Ferreira, "Diaphragm abnormalities in heart failure and aging: mechanisms and integration of cardiovascular and respiratory pathophysiology," Heart Failure Reviews, vol. 22, no. 2, pp. 191-207, 2017.

[7] B. A. Charsar, M. W. Urban, and A. C. Lepore, "Harnessing the power of cell transplantation to target respiratory dysfunction following spinal cord injury," Experimental Neurology, vol. 287, Part 2, pp. 268-275, 2017.

[8] M. Dres, E. C. Goligher, L. M. A. Heunks, and L. J. Brochard, "Critical illness-associated diaphragm weakness," Intensive Care Medicine, vol. 43, no. 10, pp. 1441-1452, 2017.

[9] L. S. Aboussouan and E. Mireles-Cabodevila, "Sleep-disordered breathing in neuromuscular disease: diagnostic and therapeutic challenges," Chest, vol. 152, no. 4, pp. 880-892, 2017.

[10] F. Laghi and M. J. Tobin, "Disorders of the respiratory muscles," American Journal of Respiratory and Critical Care Medicine, vol. 168, no. 1, pp. 10-48, 2003.

[11] S. J. Abdallah, D. S. Chan, R. Glicksman et al., "Abdominal binding improves neuromuscular efficiency of the human diaphragm during exercise," Frontiers in Physiology, vol. 8, p. 345, 2017.

[12] G. S. Supinski, P. E. Morris, S. Dhar, and L. A. Callahan, "Diaphragm dysfunction in critical illness," Chest, vol. 153, no. 4, pp. 1040-1051, 2018.

[13] C. Szabo, "Gasotransmitters in cancer: from pathophysiology to experimental therapy," Nature Reviews Drug Discovery, vol. 15, no. 3, pp. 185-203, 2016.

[14] M. D. Hartle and M. D. Pluth, "A practical guide to working with $\mathrm{H}_{2} \mathrm{~S}$ at the interface of chemistry and biology," Chemical Society Reviews, vol. 45, no. 22, pp. 6108-6117, 2016.

[15] R. Wang, "Physiological implications of hydrogen sulfide: a whiff exploration that blossomed," Physiological Reviews, vol. 92, no. 2, pp. 791-896, 2012.

[16] C. Szabo, C. Coletta, C. Chao et al., "Tumor-derived hydrogen sulfide, produced by cystathionine- $\beta$-synthase, stimulates bioenergetics, cell proliferation, and angiogenesis in colon cancer," Proceedings of the National Academy of Sciences of the United States of America, vol. 110, no. 30, pp. 1247412479, 2013.

[17] B. D. Paul and S. H. Snyder, " $\mathrm{H}_{2} \mathrm{~S}$ signalling through protein sulfhydration and beyond," Nature Reviews Molecular Cell Biology, vol. 13, no. 8, pp. 499-507, 2012.

[18] J. L. Wallace and R. Wang, "Hydrogen sulfide-based therapeutics: exploiting a unique but ubiquitous gasotransmitter," Nature Reviews Drug Discovery, vol. 14, no. 5, pp. 329-345, 2015.

[19] F. Lin, C. Liao, Y. Sun et al., "Hydrogen sulfide inhibits cigarette smoke-induced endoplasmic reticulum stress and apoptosis in bronchial epithelial cells," Frontiers in Pharmacology, vol. 8, p. 675, 2017.

[20] N. Bazhanov, M. Ansar, T. Ivanciuc, R. P. Garofalo, and A. Casola, "Hydrogen sulfide: a novel player in airway development, pathophysiology of respiratory diseases, and antiviral defenses," American Journal of Respiratory Cell and Molecular Biology, vol. 57, no. 4, pp. 403-410, 2017.

[21] T. Ivanciuc, E. Sbrana, M. Ansar et al., "Hydrogen sulfide is an antiviral and antiinflammatory endogenous gasotransmitter in the airways. Role in respiratory syncytial virus infection," American Journal of Respiratory Cell and Molecular Biology, vol. 55, no. 5, pp. 684-696, 2016.

[22] M. Singer, C. S. Deutschman, C. W. Seymour et al., "The third international consensus definitions for sepsis and septic shock (Sepsis-3)," JAMA, vol. 315, no. 8, pp. 801-810, 2016.

[23] D. D. Wu, T. Li, and X. Y. Ji, "Dendritic cells in sepsis: pathological alterations and therapeutic implications," Journal of Immunology Research, vol. 2017, 9 pages, 2017. 
[24] K. Maes, A. Stamiris, D. Thomas et al., "Effects of controlled mechanical ventilation on sepsis-induced diaphragm dysfunction in rats," Critical Care Medicine, vol. 42, no. 12, pp. e772-e782, 2014.

[25] J. Jiang, B. Yang, G. Han, M. Yang, and S. Li, "Early administration of cisatracurium attenuates sepsis-induced diaphragm dysfunction in rats," Inflammation, vol. 38, no. 1, pp. 305311, 2015.

[26] Y. Susa, Y. Masuda, H. Imaizumi, and A. Namiki, "Neutralization of receptor for advanced glycation end-products and high mobility group box-1 attenuates septic diaphragm dysfunction in rats with peritonitis," Critical Care Medicine, vol. 37, no. 9, pp. 2619-2624, 2009.

[27] K. E. Kim, Y. J. Koh, B. H. Jeon et al., "Role of CD11b ${ }^{+}$macrophages in intraperitoneal lipopolysaccharide-induced aberrant lymphangiogenesis and lymphatic function in the diaphragm," The American Journal of Pathology, vol. 175, no. 4, pp. 1733$1745,2009$.

[28] J. Shi, Y. Zhao, Y. Wang et al., "Inflammatory caspases are innate immune receptors for intracellular LPS," Nature, vol. 514, no. 7521, pp. 187-192, 2014.

[29] Y. Song, K. Karisnan, P. B. Noble et al., "In utero LPS exposure impairs preterm diaphragm contractility," American Journal of Respiratory Cell and Molecular Biology, vol. 49, no. 5, pp. 866-874, 2013.

[30] D. Wu, M. Li, W. Tian et al., "Hydrogen sulfide acts as a double-edged sword in human hepatocellular carcinoma cells through EGFR/ERK/MMP-2 and PTEN/AKT signaling pathways," Scientific Reports, vol. 7, no. 1, p. 5134, 2017.

[31] I. Javen, N. A. Williams, I. R. Young, A. R. Luff, and D. Walker, "Growth and differentiation of fast and slow muscles in fetal sheep, and the effects of hypophysectomy," The Journal of Physiology, vol. 494, no. 3, pp. 839-849, 1996.

[32] X. Zhu, H. W. H. van Hees, L. Heunks et al., "The role of calpains in ventilator-induced diaphragm atrophy," Intensive Care Medicine Experimental, vol. 5, no. 1, p. 14, 2017.

[33] B. Keam, S. A. Im, K. H. Lee et al., "Ki-67 can be used for further classification of triple negative breast cancer into two subtypes with different response and prognosis," Breast Cancer Research, vol. 13, no. 2, p. R22, 2011.

[34] M. Y. Chang, Y. H. Rhee, S. H. Yi et al., "Doxycycline enhances survival and self-renewal of human pluripotent stem cells," Stem Cell Reports, vol. 3, no. 2, pp. 353-364, 2014.

[35] M. Chen, X. Wang, D. Zha et al., “Apigenin potentiates TRAIL therapy of non-small cell lung cancer via upregulating DR4/ DR5 expression in a p53-dependent manner," Scientific Reports, vol. 6, no. 1, article 35468, 2016.

[36] P. Pitchakarn, S. Suzuki, K. Ogawa et al., "Induction of G1 arrest and apoptosis in androgen-dependent human prostate cancer by Kuguacin J, a triterpenoid from Momordica charantia leaf," Cancer Letters, vol. 306, no. 2, pp. 142-150, 2011.

[37] Y. Liu and C. He, "A review of redox signaling and the control of MAP kinase pathway in plants," Redox Biology, vol. 11, pp. 192-204, 2017.

[38] M. Vucetic, A. Stancic, V. Otasevic et al., "The impact of cold acclimation and hibernation on antioxidant defenses in the ground squirrel (Spermophilus citellus): an update," Free Radical Biology \& Medicine, vol. 65, pp. 916-924, 2013.

[39] Y. Ma, J. X. Zhang, Y. N. Liu et al., "Caffeic acid phenethyl ester alleviates asthma by regulating the airway microenvironment via the ROS-responsive MAPK/Akt pathway," Free Radical Biology \& Medicine, vol. 101, pp. 163-175, 2016.

[40] S. K. Jalmi and A. K. Sinha, "ROS mediated MAPK signaling in abiotic and biotic stress-striking similarities and differences," Frontiers in Plant Science, vol. 6, p. 769, 2015.

[41] G. L. Johnson and R. Lapadat, "Mitogen-activated protein kinase pathways mediated by ERK, JNK, and p38 protein kinases," Science, vol. 298, no. 5600, pp. 1911-1912, 2002.

[42] X. Liu, B. Ma, A. B. Malik et al., "Bidirectional regulation of neutrophil migration by mitogen-activated protein kinases," Nature Immunology, vol. 13, no. 5, pp. 457-464, 2012.

[43] B. Seyoum, A. Fite, and A. B. Abou-Samra, "Effects of 3T3 adipocytes on interleukin-6 expression and insulin signaling in L6 skeletal muscle cells," Biochemical and Biophysical Research Communications, vol. 410, no. 1, pp. 13-18, 2011.

[44] S. E. Hussey, H. Liang, S. R. Costford et al., "TAK-242, a smallmolecule inhibitor of Toll-like receptor 4 signalling, unveils similarities and differences in lipopolysaccharide- and lipid induced inflammation and insulin resistance in muscle cells," Bioscience Reports, vol. 33, no. 1, pp. 37-47, 2012.

[45] V. Samokhvalov, P. J. Bilan, J. D. Schertzer, C. N. Antonescu, and A. Klip, "Palmitate- and lipopolysaccharide-activated macrophages evoke contrasting insulin responses in muscle cells," American Journal of Physiology-Endocrinology and Metabolism, vol. 296, no. 1, pp. E37-E46, 2009.

[46] R. Fiorotto, R. Scirpo, M. Trauner et al., "Loss of CFTR affects biliary epithelium innate immunity and causes TLR4-NF- $\kappa \mathrm{B}$ mediated inflammatory response in mice," Gastroenterology, vol. 141, no. 4, pp. 1498-1508.e5, 2011.

[47] N. L. Xiang, J. Liu, Y. J. Liao et al., "Abrogating ClC-3 inhibits LPS-induced inflammation via blocking the TLR4/ NF- $\kappa$ B pathway," Scientific Reports, vol. 6, no. 1, article 27583, 2016.

[48] K. W. Zeng, H. Fu, G. X. Liu, and X. M. Wang, "Icariin attenuates lipopolysaccharide-induced microglial activation and resultant death of neurons by inhibiting TAK1/IKK/NF- $\kappa \mathrm{B}$ and JNK/p38 MAPK pathways," International Immunopharmacology, vol. 10, no. 6, pp. 668-678, 2010.

[49] G. Shu, Y. Tang, Y. Zhou, C. Wang, and J. G. Song, "Zac1 is a histone acetylation-regulated NF- $\kappa$ B suppressor that mediates histone deacetylase inhibitor-induced apoptosis," Cell Death \& Differentiation, vol. 18, no. 12, pp. 1825-1835, 2011.

[50] A. L. Andrade-Lopes, M. Pires-Oliveira, F. S. MenezesRodrigues, and R. O. Godinho, "Functional characterization of heterotrimeric G-proteins in rat diaphragm muscle," Respiratory Physiology \& Neurobiology, vol. 175, no. 2, pp. 212-219, 2011.

[51] V. Moresi, G. Garcia-Alvarez, A. Pristerà et al., "Modulation of caspase activity regulates skeletal muscle regeneration and function in response to vasopressin and tumor necrosis factor," PLoS One, vol. 4, no. 5, article e5570, 2009.

[52] L. Trapani, M. Segatto, P. La Rosa et al., "3-Hydroxy 3methylglutaryl coenzyme A reductase inhibition impairs muscle regeneration," Journal of Cellular Biochemistry, vol. 113, no. 6, pp. 2057-2063, 2012.

[53] D. Wu, W. Si, M. Wang, S. Lv, A. Ji, and Y. Li, "Hydrogen sulfide in cancer: friend or foe?," Nitric Oxide, vol. 50, pp. 38-45, 2015.

[54] D. Wu, Y. Gao, Y. Qi, L. Chen, Y. Ma, and Y. Li, "Peptidebased cancer therapy: opportunity and challenge," Cancer Letters, vol. 351, no. 1, pp. 13-22, 2014. 
[55] J. F. Lovell, L. P. Billen, S. Bindner et al., "Membrane binding by tBid initiates an ordered series of events culminating in membrane permeabilization by Bax," Cell, vol. 135, no. 6, pp. 1074-1084, 2008.

[56] C. D. Fan, Y. Li, X. T. Fu et al., "Reversal of beta-amyloidinduced neurotoxicity in PC12 cells by curcumin, the important role of ROS-mediated signaling and ERK pathway," Cellular and Molecular Neurobiology, vol. 37, no. 2, pp. 211-222, 2017.

[57] S. E. Tang, C. P. Wu, S. Y. Wu et al., "Stanniocalcin-1 ameliorates lipopolysaccharide-induced pulmonary oxidative stress, inflammation, and apoptosis in mice," Free Radical Biology \& Medicine, vol. 71, pp. 321-331, 2014.

[58] I. Zanoni, R. Ostuni, G. Capuano et al., "CD14 regulates the dendritic cell life cycle after LPS exposure through NFAT activation," Nature, vol. 460, no. 7252, pp. 264-268, 2009.

[59] M. L. Circu and T. Y. Aw, "Reactive oxygen species, cellular redox systems, and apoptosis," Free Radical Biology \& Medicine, vol. 48, no. 6, pp. 749-762, 2010.

[60] C. J. Dunnill, K. Ibraheem, A. Mohamed, J. Southgate, and N. T. Georgopoulos, "A redox state-dictated signalling pathway deciphers the malignant cell specificity of CD40mediated apoptosis," Oncogene, vol. 36, no. 18, pp. 25152528, 2017.

[61] L. Chen, P. Liu, X. Feng, and C. Ma, "Salidroside suppressing LPS-induced myocardial injury by inhibiting ROS-mediated $\mathrm{PI} 3 \mathrm{~K} / \mathrm{Akt} / \mathrm{mTOR}$ pathway in vitro and in vivo," Journal of Cellular and Molecular Medicine, vol. 21, no. 12, pp. 3178-3189, 2017.

[62] W. Hao, X. Yuan, L. Yu et al., "Licochalcone A-induced human gastric cancer BGC-823 cells apoptosis by regulating ROSmediated MAPKs and PI3K/AKT signaling pathways," Scientific Reports, vol. 5, no. 1, article 10336, 2015.

[63] R. Tarabees, D. Hill, C. Rauch, P. A. Barrow, and P. T. Loughna, "Endotoxin transiently inhibits protein synthesis through Akt and MAPK mediating pathways in C2C12 myotubes," American Journal of Physiology-Cell Physiology, vol. 301, no. 4, pp. C895-C902, 2011.

[64] K. Jiang, T. Zhang, N. Yin et al., "Geraniol alleviates LPSinduced acute lung injury in mice via inhibiting inflammation and apoptosis," Oncotarget, vol. 8, no. 41, pp. 71038-71053, 2017.

[65] P. Cheng, T. Wang, W. Li et al., "Baicalin alleviates lipopolysaccharide-induced liver inflammation in chicken by suppressing TLR4-mediated NF- $\kappa \mathrm{B}$ pathway," Frontiers in Pharmacology, vol. 8, p. 547, 2017.

[66] K. Karisnan, T. Mahzabin, A. J. Bakker et al., "Gestational age at time of in utero lipopolysaccharide exposure influences the severity of inflammation-induced diaphragm weakness in lambs," American Journal of Physiology-Regulatory, Integrative and Comparative Physiology, vol. 314, no. 4, pp. R523-R532, 2018. 


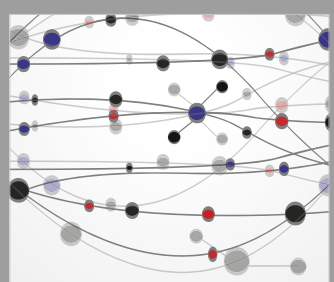

The Scientific World Journal
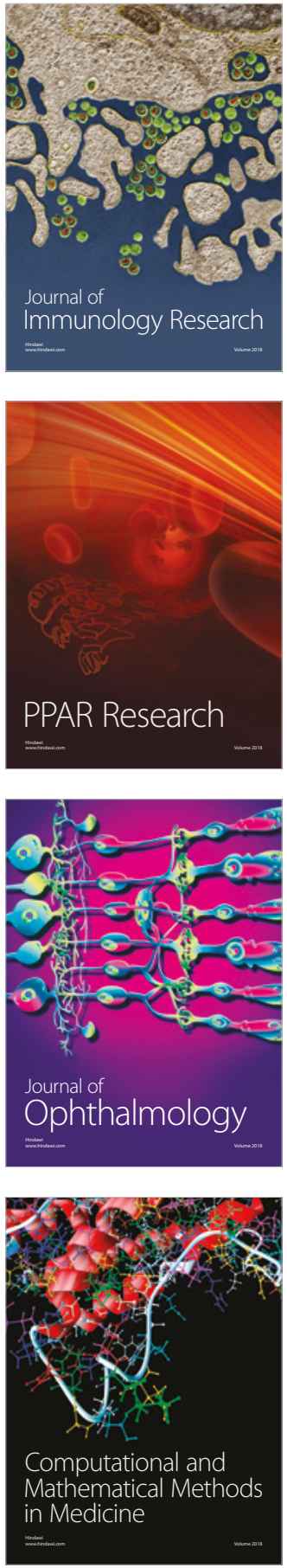

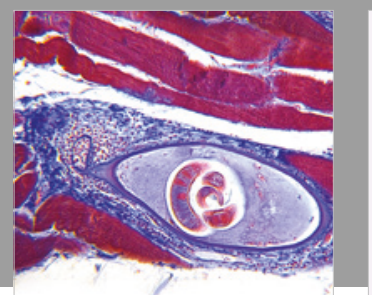

Gastroenterology Research and Practice

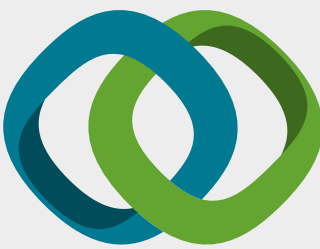

\section{Hindawi}

Submit your manuscripts at

www.hindawi.com
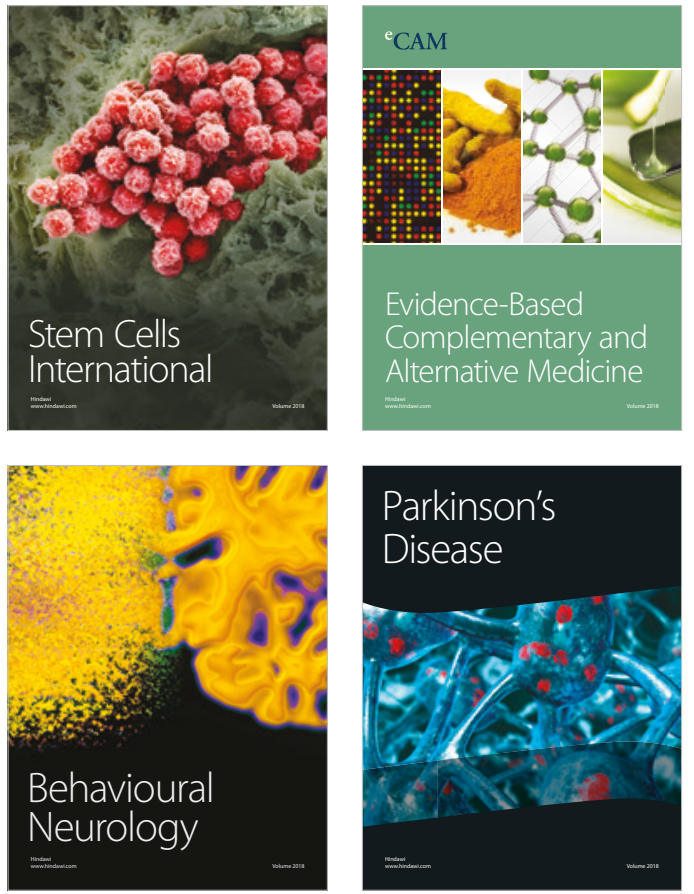

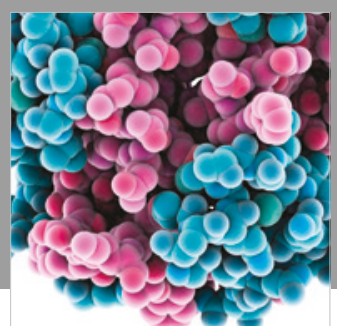

ournal of

Diabetes Research

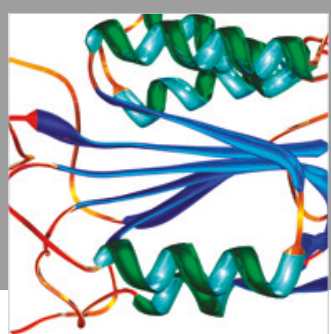

Disease Markers
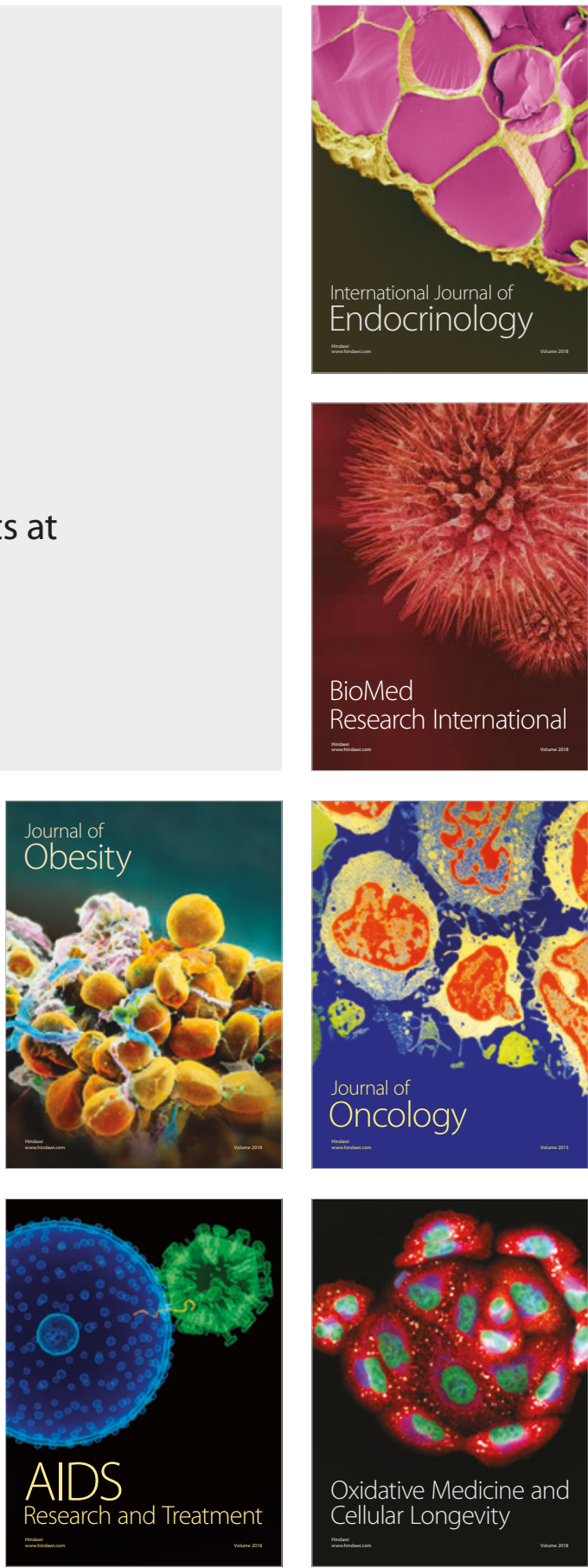